\title{
Hooking Together Sigmoidal Monomers into Supramolecular Polymers
}

Marco Carini, Mauro Marongiu, Karol Strutyński, Akinori Saeki, Manuel Melle-Franco, Aurelio Mateo-Alonso

Submitted date: 09/09/2019 Posted date: 11/09/2019

Licence: CC BY-NC-ND 4.0

Citation information: Carini, Marco; Marongiu, Mauro; Strutyński, Karol; Saeki, Akinori; Melle-Franco, Manuel; Mateo-Alonso, Aurelio (2019): Hooking Together Sigmoidal Monomers into Supramolecular Polymers. ChemRxiv. Preprint.

Supramolecular polymers have a lot of potential in the development of new materials because of their inherent recyclability and their self-healing and stimuli-responsive properties. Supramolecular conductive polymers are generally obtained by the assembly of individual disk-like $\pi$-conjugated molecules into columnar arrays that provide an optimal channel for electronic transport. We report a new approach to prepare supramolecular polymers by hooking together sigmoidal monomers into 1D arrays of $\pi$-stacked anthracene and acridine units, which give rise to micrometer-sized fibrils that show pseudoconductivities in line with other conducting materials. This approach paves the way for the design of new supramolecular polymers constituted by acene derivatives with enhanced excitonic and electronic transporting properties.

File list (2)

1 Manuscript 8.pdf (1.70 MiB)

view on ChemRxiv • download file 


\title{
Hooking Together Sigmoidal Monomers into Supramolecular Polymers
}

\author{
Marco Carini, ${ }^{[a]}$ Mauro Marongiu, ${ }^{[a]}$ Karol Strutyński, ${ }^{[b]}$ Akinori Saeki, ${ }^{[c]}$ Manuel Melle-Franco, ${ }^{[b]}$ and \\ Aurelio Mateo-Alonso ${ }^{*[a][d]}$
}

\begin{abstract}
Supramolecular polymers have a lot of potential in the development of new materials because of their inherent recyclability and their self-healing and stimuli-responsive properties. Supramolecular conductive polymers are generally obtained by the assembly of individual disk-like $\pi$-conjugated molecules into columnar arrays that provide an optimal channel for electronic transport. We report a new approach to prepare supramolecular polymers by hooking together sigmoidal monomers into $1 \mathrm{D}$ arrays of $\pi$-stacked anthracene and acridine units, which give rise to micrometer-sized fibrils that show pseudoconductivities in line with other conducting materials. This approach paves the way for the design of new supramolecular polymers constituted by acene derivatives with enhanced excitonic and electronic transporting properties.
\end{abstract}

Supramolecular polymers play a pivotal role in materials science because of their inherent recyclability and their self-healing and stimuli-responsive properties. ${ }^{[1-2]}$ Such properties are a direct consequence of their non-covalent nature and of the reversibility of the monomer to polymer equilibrium. Furthermore, the high directionality of non-covalent interactions, such as hydrogen bonds or $\pi$-stacking allows constructing ordered and shapepersistent nanometric and even micrometric polymeric assemblies with high precision by spontaneous self-assembly of molecular monomers. ${ }^{[3-4]}$

All the above-mentioned features make supramolecular polymers an ideal platform to develop materials for electronic applications, since efficient electronic transport is dominated by the precise spatial organization of organic semiconductors. For instance, lamellar $\pi$-stacking has been identified as an optimal molecular arrangement for electronic transport since it favours intermolecular electronic coupling. ${ }^{[5-17]}$ Most supramolecular polymers for electronic applications involve the assembly of individual disk-like $\pi$-conjugated molecules (through hydrogen bonding, solvophobic, m-stacking and/or CT interactions) into columnar arrays in order to open an optimal channel for electronic transport.

\footnotetext{
[a] Dr. M. Carini, M. Marongiu, Prof. Dr. A. Mateo-Alonso POLYMAT, University of the Basque Country UPV/EHU Avenida de Tolosa 72, 20018 Donostia-San Sebastian (Spain) E-mail: amateo@polymat.eu

[b] Prof. Dr. M. Melle-Franco and Dr. K. Strutyński CICECO - Aveiro Institute of Materials, Department of Chemistry, University of Aveiro 3810-193 Aveiro, Portugal

[c] Prof. Dr. A. Saeki Department of Applied Chemistry Graduate School of Engineering Osaka University Suita, Osaka 565-0871 (Japan)

[d] Prof. Dr. A. Mateo-Alonso Ikerbasque, Basque Foundation for Science Bilbao (Spain)
}

Scheme 1. Synthesis and structure of supramolecular polymer (Ac-A-Ac) $n$.

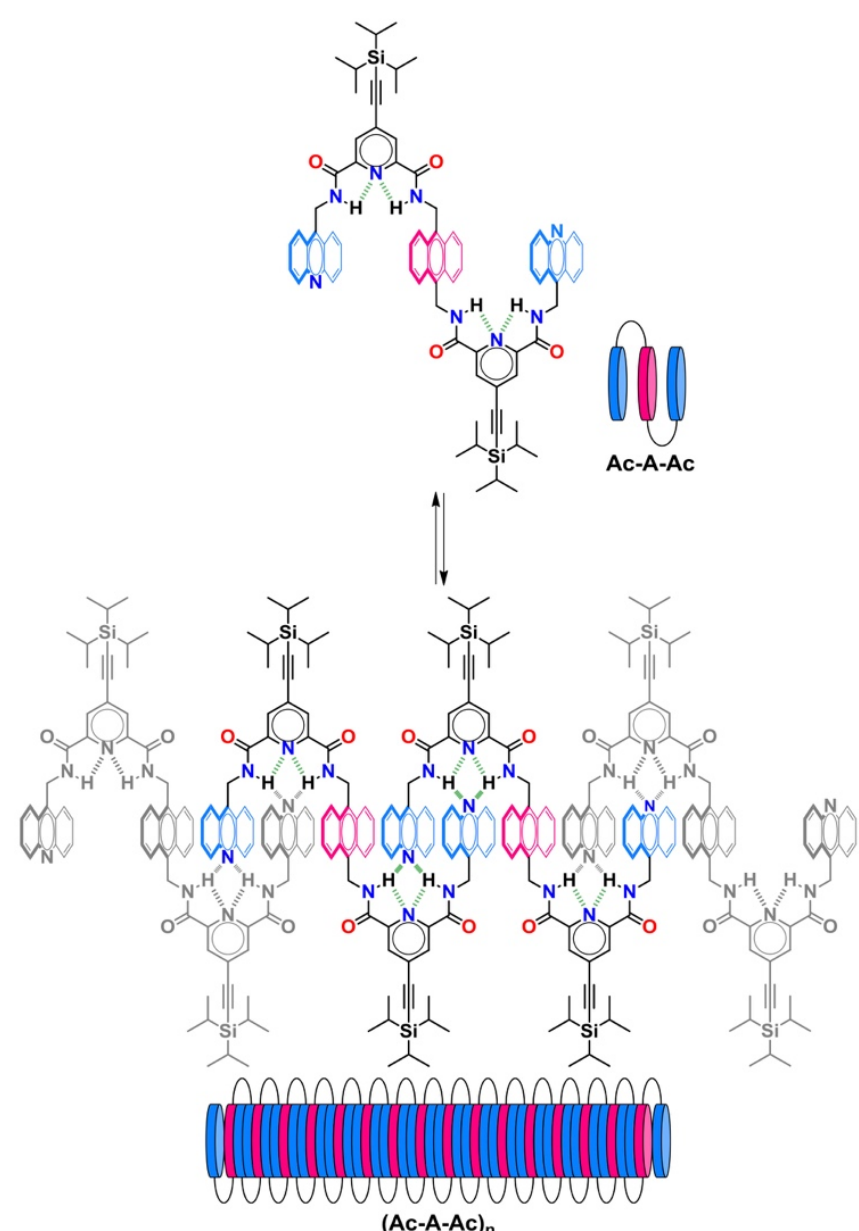

Herein, we report a new family of supramolecular (AC-AAc)n polymers that are obtained by hooking sigmoidal Ac-A-Ac monomers into a one-dimensional array of stacked anthracene (A) and acridine (Ac) units (Scheme 1). The Ac-A-Ac monomers are constituted by two external acridine units stitched to a central anthracene unit by 2,6-pyridinedicarboxamides. First, the Ac-AAc monomers fold into a sigmoidal hook-like conformation by intramolecular hydrogen bonds between the amides and the pyridinic nitrogen that gives rise to two adjacent antiparallel cavities of $\sim 7 \AA$. Then, the folded Ac-A-Ac monomer can be hooked into another folded Ac-A-Ac monomer by hydrogen bonds between the acridine nitrogen of one monomer and the amides of another monomer and by $\pi$-stacking. This monomer assembly mode leaves always two available cavities that promote the incorporation of additional monomers and therefore the formation of supramolecular (Ac-A-Ac)n polymers. In fact, the AcA-Ac monomers spontaneously self-assemble to provide 
micrometer long nanofibers with charge transporting properties similar to those of conducting polymers.

In addition to the self-assembling structural features described above, anthracene and acridine units were selected because of their excellent structural and electronic complementarity since they are constituted by three linearly fused rings and also because of their well-balanced properties in terms of charge transport, stability and solubility. Also, triisopropylsilyl (TIPS) groups have been introduced in the pyridine units to increase the solubility. To ensure that the Ac-A-Ac monomers are able to self-assemble into desired (Ac-A-Ac) $n$ polymers, a series of model experiments were carried out with A-A and Ac-A tweezer-like compounds (Figures 1 and 2 ) in order to understand the interactions between the different units and motifs. A-A has been prepared following a route described previously by some of us ${ }^{[18]}$ while all details of the synthesis and characterization of the Ac-A and Ac-A-Ac are given in the supporting information.

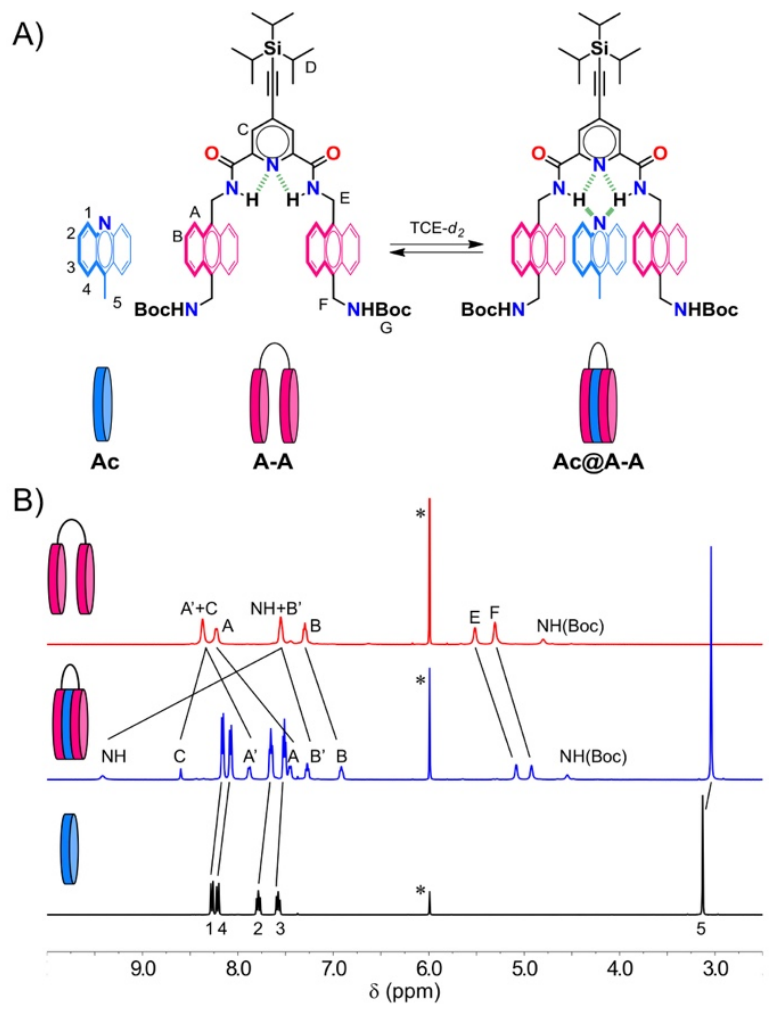

Figure 1. A) Scheme showing the assembly process between A-A and 9methylacridine. B) ${ }^{1} \mathrm{H}-\mathrm{NMR}$ of A-A $\left(5 \times 10^{-3} \mathrm{M}, 25^{\circ} \mathrm{C}\right)$ in TCE- $d_{2}$ (red); ${ }^{1} \mathrm{H}-\mathrm{NMR}$ of A-A $\left(5 \times 10^{-3} \mathrm{M}, 25^{\circ} \mathrm{C}\right)$ with an excess (6 eq) of 9-methylacridine in TCE-d (blue); ${ }^{1} \mathrm{H}-\mathrm{NMR}$ of 9 -methylacridine in TCE- $d_{2}$ (black). The asterisks indicate residual solvent peaks.

To ensure that acridines able to self-assemble into the cavity of the folded Ac-A-Ac monomers, the supramolecular interaction between 9-methylacridine into the model A-A twezeers was studied (Figure 1). The NMR spectrum of a mixture of $\mathbf{A}-\mathbf{A}$ in the presence of an excess of 9-methylacridine shows that the amide $\mathrm{NH}$ signals of $\mathbf{A}-\mathbf{A}$ are deshielded in comparison to those of the free $\mathbf{A}-\mathbf{A}$, which is consistent with the formation of hydrogen bonds with the nitrogen of acridine. Furthermore, the anthracene signals $\left(A, A^{\prime}, B\right.$ and $\left.B^{\prime}\right)$ and the 9-methylacridine signals $(1,2,3$ and 4$)$ in the mixture are shielded in comparison to those of free A-A and free 9-methylacridine, respectively. These changes can be explained in terms of anisotropy because of the close proximity of the anthracene and acridine units as the result of $\pi$-stacking. NMR titration of A-A with increasing amounts of 9-methylacridine in 1,1,2,2-tetrachloroethane- $d_{2}$ (TCE- $\left.d_{2}\right)$ (Figure S1) also evidenced similar changes in the NMR spectra consistent with the formation of the complex. From the titration experiments, an association constant $\left(K_{\mathrm{a}}\right)$ of $1.4 \times 10^{2} \mathrm{M}^{-1}$ was estimated. ${ }^{[19-21]}$

One of the key steps in the formation of the (Ac-A-Ac) $n$ polymers rely on the formation of an assembly with four interacting anthracene and acridine units held together by two sets of intermolecular hydrogen bonds. Again, to ensure that the formation of such multimode assembly is possible, a model Ac-A tweezer that shows exactly the same self-recognition pattern as $\mathbf{A c}-\mathbf{A}-\mathbf{A c}$ but that upon self-assembly will evolve into the (Ac-A $)_{2}$ dimer rather than into the (Ac-A-Ac)n (Figure 2). To evaluate the homodimerisation of the Ac-A, ${ }^{1} \mathrm{H}$ NMRs in different solvents were recorded at different concentrations. The ${ }^{1} \mathrm{H}$ NMR spectrum recorded in dimethylsulfoxide- $d_{6}$ (DMSO- $d_{6}$ ) show the individualised (undimerised) Ac-A since the aromatic signals (A, $B, C, D, G$ and $H$ ) resonate all at the typical chemical shift values of anthracene and acridine derivatives (8.5-7.4 ppm) in this solvent. This is because of the high hydrogen bond basicity of DMSO disturbs the intermolecular hydrogen bond, favouring solvation rather than dimerization. The ${ }^{1} \mathrm{H}$ NMR spectrum of AcA recorded in TCE- $d_{2}$, a solvent with a low hydrogen bond basicity that does not interfere with the hydrogen bonds, evidence the homodimerization of Ac-A into (Ac-A $)_{2}$. In fact, the $\mathrm{NH}$ signals resonate at chemical shifts consistent with the formation of hydrogen bonds ( 10.09 and $9.46 \mathrm{ppm}$ ). Moreover, the anthracene and acridine signals are broadened and appear strongly shielded (at 7.6-6.6 ppm) as an effect of anisotropy that support m-stacking. The ability of Ac-A to dimerise is also evidenced by matrixassisted laser desorption ionization (coupled to a time-of-flight analyser) mass spectrometry (MALDI-TOF MS) that shows the $[2 \mathrm{M}+\mathrm{Na}]^{+}$mass peak corresponding to $(\mathrm{Ac}-\mathrm{A})_{2}$ in the gas phase, besides the $[\mathrm{M}+\mathrm{H}]^{+}$and $[\mathrm{M}+\mathrm{Na}]^{+}$ions (Figure $\mathrm{S} 2$ ).

The homodimerization features in the ${ }^{1} \mathrm{H}$ NMR spectra are persistent upon dilution down to the NMR detection limit $\left(\sim 10^{-4} M\right)$, which indicate that the dimerization constant $\left(K_{d}\right)$ is $>10^{4}$ (Figure S3). To overcome this, $K_{d}$ was estimated by means UV-vis spectroscopy through dilution experiments from $10^{-4}$ to $10^{-6} \mathrm{M}$ (Figure S4). By this method, a dimerization constant $K_{d}=8.56 \mathrm{x}$ $10^{5} \mathrm{M}^{-1}$ was estimated, ${ }^{[19-21]}$ which is almost four orders of magnitude higher than the constant of the Ac@A-A complex. 
A)

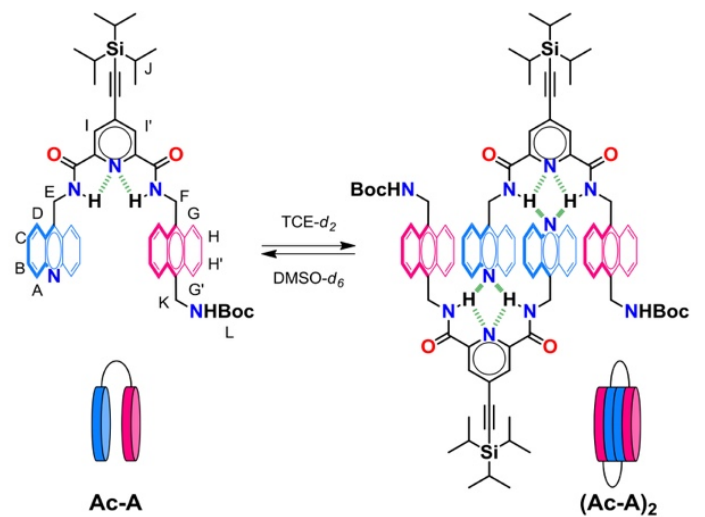

B)
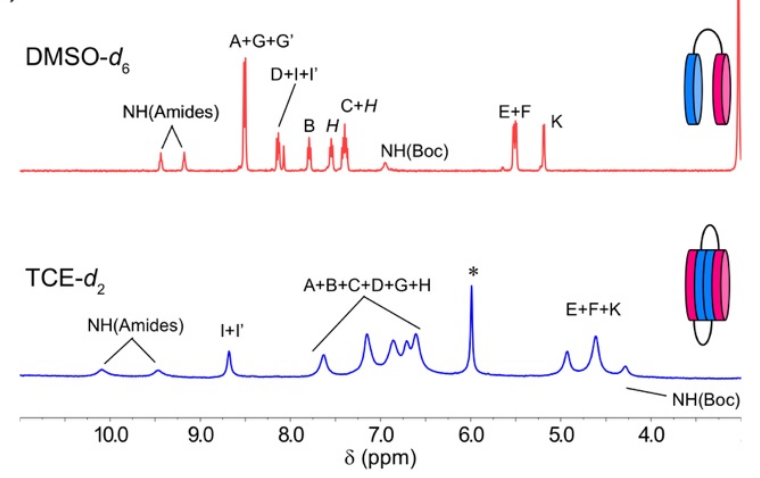

Figure 2. A) Scheme showing the dimerisation of Ac-A. B) ${ }^{1} \mathrm{H}-\mathrm{NMR}$ of Ac-A (80 $\left.{ }^{\circ} \mathrm{C}\right)$ in DMSO- $d_{6}$ (red) and of Ac-A $\left(25^{\circ} \mathrm{C}\right)$ in TCE- $d_{2}$ (blue). The asterisks indicate residual solvent peaks.

The studies on the model compounds evidenced that the Ac-A-Ac monomer will be able to self-assemble in a similar fashion to Ac-A but providing two cavities that will enable the inclusion of additional monomers to provide (AC-A-Ac) $n$ (Scheme 1). In contrast to Ac-A, the Ac-A-Ac monomer was only found to be soluble during chromatographic purification from the crude mixture. Remarkably, after evaporating the solvent (chloroform) from the fractions containing Ac-A-Ac, a virtually insoluble material was obtained that could not be re-dissolved in any chlorinated solvent. This irreversible change of solubility of the Ac-A-Ac monomer is consistent with the formation of the (Ac-A$A c)_{n}$ supramolecular polymer upon the evaporation of the solvent. Definitive evidence of the formation of the (Ac-A-Ac) $n$ polymer came from atomic force microscopy (AFM) and scanning electron microscopy (SEM). The AFM and SEM images of the (Ac-A-Ac) n dispersions in TCE revealed the presence of fibrils with a thickness of 20-40 $\mathrm{nm}$ that extend in length over several micrometers (Figures 3 and S5-S8). While the images of the deposited samples of Ac-A using the same conditions showed an unstructured film-like coverage of the surface with no evident morphology (Figure S9). This is consistent with the fact that Ac-A can only dimerise and not polymerise.
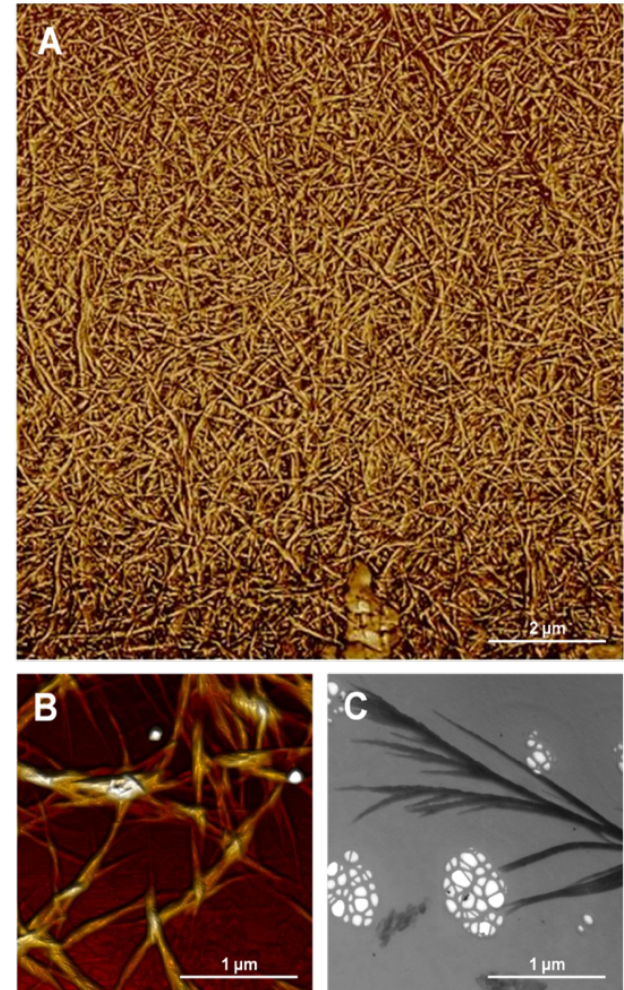

Figure 3. Morphology of the (Ac-A-Ac) $n$ supramolecular polymer. A) AFM on mica $10 \times 10 \mu \mathrm{m}$. B) AFM on mica $2.5 \times 2.5 \mu \mathrm{m}$. C) SEM on holey carbon film coated copper grid $2.5 \times 2.5 \mu \mathrm{m}$.

The (Ac-A-Ac) $n$ can be disassembled into smaller oligomers and even into monomers by increasing the temperature or by using solvents with a high hydrogen bond basicity. For instance, the (Ac-A-Ac)n polymer can be partially disassembled at high temperatures into smaller oligomers as illustrated by VTNMR experiments in TCE- $d_{2}$, where the broad signals in the aromatic region split into partially resolved signals that resonate at the chemical shifts expected for the acridine and anthracene units (Figure S10). Also, (Ac-A-Ac)n polymer could be completely dissolved in trifluoroacetic acid (TFA) that strongly disturbs the hydrogen bonds and protonates the acridine nitrogen, as revealed by the ${ }^{1} \mathrm{H}$ NMR in TFA- $d_{1}$, where structure of the disassembled Ac-A-Ac monomer was observed (Figure S11).

The intrinsic charge transport properties of the (Ac-A-Ac) $n$ polymer were evaluated by means of flash-photolysis timeresolved microwave conductivity (FP-TRMC) measurements. This method measures directly the pseudoconductivity (defined as $\phi \Sigma \mu$, where $\phi$ and $\Sigma \mu$ are the photocarrier-generation yield and the sum of the mobilities of the generated charge carriers, respectively) without introducing electrodes. The $\phi \Sigma \mu$ maxima can be considered the minimum mobility of the material since the $\phi$ values are submultiples of the unit. A pseudoconductivity value $\varphi \Sigma \mu=2.40 \times 10^{-4} \mathrm{~cm}^{2} \mathrm{~V}^{-1} \mathrm{~s}^{-1}$ was estimated for the (Ac-A-Ac) $\mathrm{n}$ polymer from the resultant rise and decay profiles of transient conductivities (Figure 4A). These $\phi \Sigma \mu$ values are in line with other conducting materials such as nanographenes, ${ }^{[22-23]}$ stacked pseudorotaxanes, ${ }^{[24]}$ peropyrene fibers, ${ }^{[25-26]}$ and conjugated polymers. ${ }^{[27]}$ 
A)

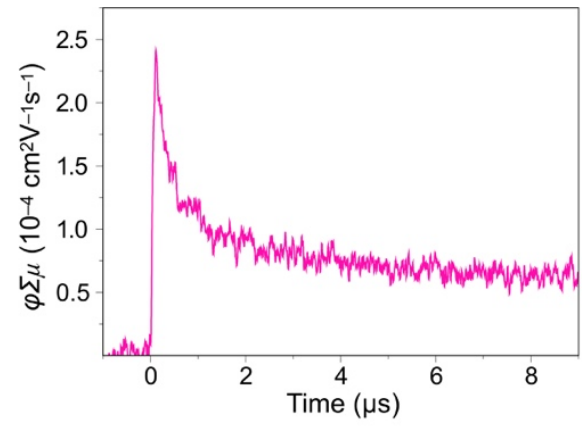

B)

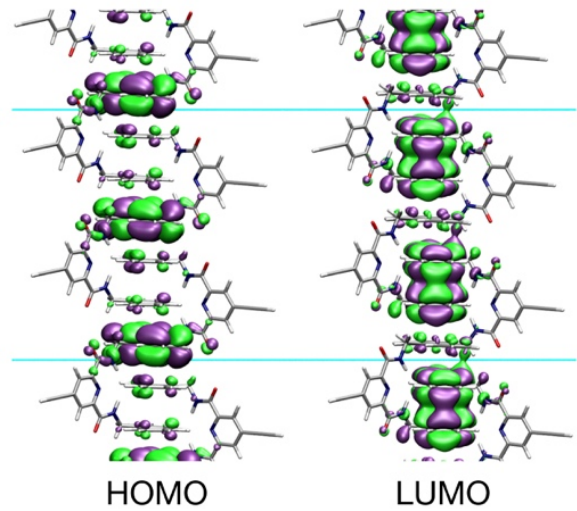

Figure 4. A) TRMC of (Ac-A-Ac) n. B) Frontier orbitals of (Ac-A-Ac') $)_{n}$.

To provide a picture of the electronic structure of Ac-A-Ac, theoretical calculations were carried out. For this, we first built a 1D crystal by replicating a suitably oriented molecule containing the aromatic core of Ac-A-Ac. Then, we explored configurational space by molecular dynamics and systematic minimizations with different $1 \mathrm{D}$ periodic lengths with a semiempirical tight binding model. The best minima found were then studied at the DFT GGA level while orbitals and corresponding energies were obtained with a hybrid Hamiltonian. The electronic structure and the orbitals of the frontier orbitals for the (Ac-A-Ac') $n$, in which the TIPS groups have been substituted by hydrogen, are qualitatively similar for studied cases (full details can be found in the supporting information). For each extra molecule in the periodic unit cell there is an extra nearly-degenerate HOMO and LUMO level. HOMO orbitals have consistently large densities on the anthracene moieties, while LUMO orbitals have consistently large densities on the two acridine neighbouring moieties (Figures 4B and S12). Remarkably, for all models, the electron densities of the frontier orbitals are spread throughout the stacked anthracene and acridine units, which act as channels for electronic transport.

To conclude, a new approach to prepare supramolecular polymers by hooking together sigmoidal Ac-A-Ac monomers into 1D arrays of stacked anthracene and acridine units has been reported. The Ac-A-Ac monomers are able to self-assemble by a combination of hydrogen bonds and m-stacking as demonstrated by a series of studies carried out on model compounds that show how A-A can complex acridine and Ac-A can dimerise, in a similar fashion as the Ac-A-Ac monomers. Furthermore, the Ac-A-Ac monomers have shown to form (Ac-A-Ac)n spontaneously giving rise to micrometer-sized fibrils that show pseudoconductivities in line with other conducting materials. The approach reported here will pave the way for the preparation of supramolecular polymers constituted of acene derivatives, which combine the properties in electronic and excitonic transport and singlet fission of acenes with the recyclability and self-healing properties of supramolecular polymers.

\section{Acknowledgements}

We are grateful to the Basque Science Foundation for Science (Ikerbasque), POLYMAT, the University of the Basque Country (Grupo de Investigación GIU17/054 and SGIker), Gobierno de España (Ministerio de Economía y Competitividad CTQ201677970-R), Gobierno Vasco (BERC program), Diputación Foral de Guipúzcoa (OF215/2016(ES)) and the Portuguese Foundation for Science and Technology (FCT), under the projects PTDC/FISNAN/4662/2014, IF/00894/2015, and FCT Ref. UID/CTM/50011/2019 for CICECO - Aveiro Institute of Materials. This project has been co-funded by the Erasmus+ programme of the European Union (contract 2018-1-IT02-KA103-047028). This project has received funding from the European Union's Horizon 2020 research and innovation programme under grant agreement No 664878 and from the European Research Council (ERC) under the European Union's Horizon 2020 research and innovation programme (grant agreement $n^{\circ} 722951$ ). We thank Professor Pall Thodarson for help using the online tools for supramolecular chemistry research and analysis available at http://supramolecular.org

Keywords: supramolecular polymer $\cdot \pi$-stacking $\cdot$ hydrogen bond $\cdot$ anthracene $\cdot$ acridine

[1] T. Aida, E. W. Meijer, S. I. Stupp, Science 2012, 335, 813-817.

[2] L. Yang, X. Tan, Z. Wang, X. Zhang, Chem. Rev. 2015, 115, 71967239.

[3] D. D. Prabhu, K. Aratsu, Y. Kitamoto, H. Ouchi, T. Ohba, M. J. Hollamby, N. Shimizu, H. Takagi, R. Haruki, S.-i. Adachi, S. Yagai, Science Adv. 2018, 4

[4] N. Oya, T. Ikezaki, N. Yoshie, Polymer Journal 2013, 45, 955-961.

[5] M. Mas-Torrent, C. Rovira, Chem. Rev. 2011, 111, 4833-4856.

[6] C. Wang, H. Dong, W. Hu, Y. Liu, D. Zhu, Chem. Rev. 2012, 112, 22082267.

[7] I. Yavuz, B. N. Martin, J. Park, K. N. Houk, J. Am. Chem. Soc. 2015, 137, 2856-2866

[8] R. Pfattner, S. T. Bromley, C. Rovira, M. Mas-Torrent, Adv. Funct. Mater. 2016, 26, 2256-2275.

[9] C. Sutton, C. Risko, J.-L. Brédas, Chem. Mater. 2016, 28, 3-16

[10] J. P. Hill, W. Jin, A. Kosaka, T. Fukushima, H. Ichihara, T. Shimomura, K. Ito, T. Hashizume, N. Ishii, T. Aida, Science 2004, 304, 1481-1483.

[11] K. Balakrishnan, A. Datar, R. Oitker, H. Chen, J. Zuo, L. Zang, J. Am. Chem. Soc. 2005, 127, 10496-10497.

[12] F. Garcia, J. Buendia, S. Ghosh, A. Ajayaghosh, L. Sanchez, Chem. Commun. 2013, 49, 9278-9280.

[13] B. W. Messmore, J. F. Hulvat, E. D. Sone, S. I. Stupp, J. Am. Chem. Soc. 2004, 126, 14452-14458.

[14] F. S. Schoonbeek, J. H. van Esch, B. Wegewijs, D. B. A. Rep, M. P. de Haas, T. M. Klapwijk, R. M. Kellogg, B. L. Feringa, Angew. Chem. Int. Ed. Engl. 1999, 38, 1393-1397.

[15] S. Xiao, J. Tang, T. Beetz, X. Guo, N. Tremblay, T. Siegrist, Y. Zhu, M. Steigerwald, C. Nuckolls, J. Am. Chem. Soc. 2006, 128, 10700-10701.

[16] L. Zang, Y. Che, J. S. Moore, Acc. Chem. Res. 2008, 41, 1596-1608.

[17] A. Jain, S. J. George, Materials Today 2015, 18, 206-214.

[18] M. Carini, M. P. Ruiz, I. Usabiaga, J. A. Fernández, E. J. Cocinero, M. Melle-Franco, I. Diez-Perez, A. Mateo-Alonso, Nat. Commun. 2017, 8 , 15195.

[19] http://supramolecular.org. 
[20] D. Brynn Hibbert, P. Thordarson, Chem. Commun. 2016, 52, 1279212805.

[21] P. Thordarson, Chem. Soc. Rev. 2011, 40, 1305-1323.

[22] D. Cortizo-Lacalle, J. P. Mora-Fuentes, K. Strutyński, A. Saeki, M. Melle-Franco, A. Mateo-Alonso, Angew. Chem. Int. Ed. 2018, 57, 703708.

[23] J. P. Mora-Fuentes, A. Riaño, D. Cortizo-Lacalle, A. Saeki, M. MelleFranco, A. Mateo-Alonso, Angew. Chem. Int. Ed. 2019, 58, 552-556.
[24] C. Gozalvez, J. L. Zafra, A. Saeki, M. Melle-Franco, J. Casado, A. Mateo-Alonso, Chem. Sci. 2019, 10, 2743-2749.

[25] M. Martínez-Abadía, G. Antonicelli, A. Saeki, A. Mateo-Alonso, Angew. Chem. Int. Ed. 2018, 57, 8209-8213.

[26] M. Martínez-Abadía, G. Antonicelli, A. Saeki, M. Melle-Franco, A Mateo-Alonso, J. Org. Chem. 2019, 84, 3270-3274.

[27] A. Saeki, Y. Koizumi, T. Aida, S. Seki, Acc. Chem. Res. 2012, 45 1193-1202. 

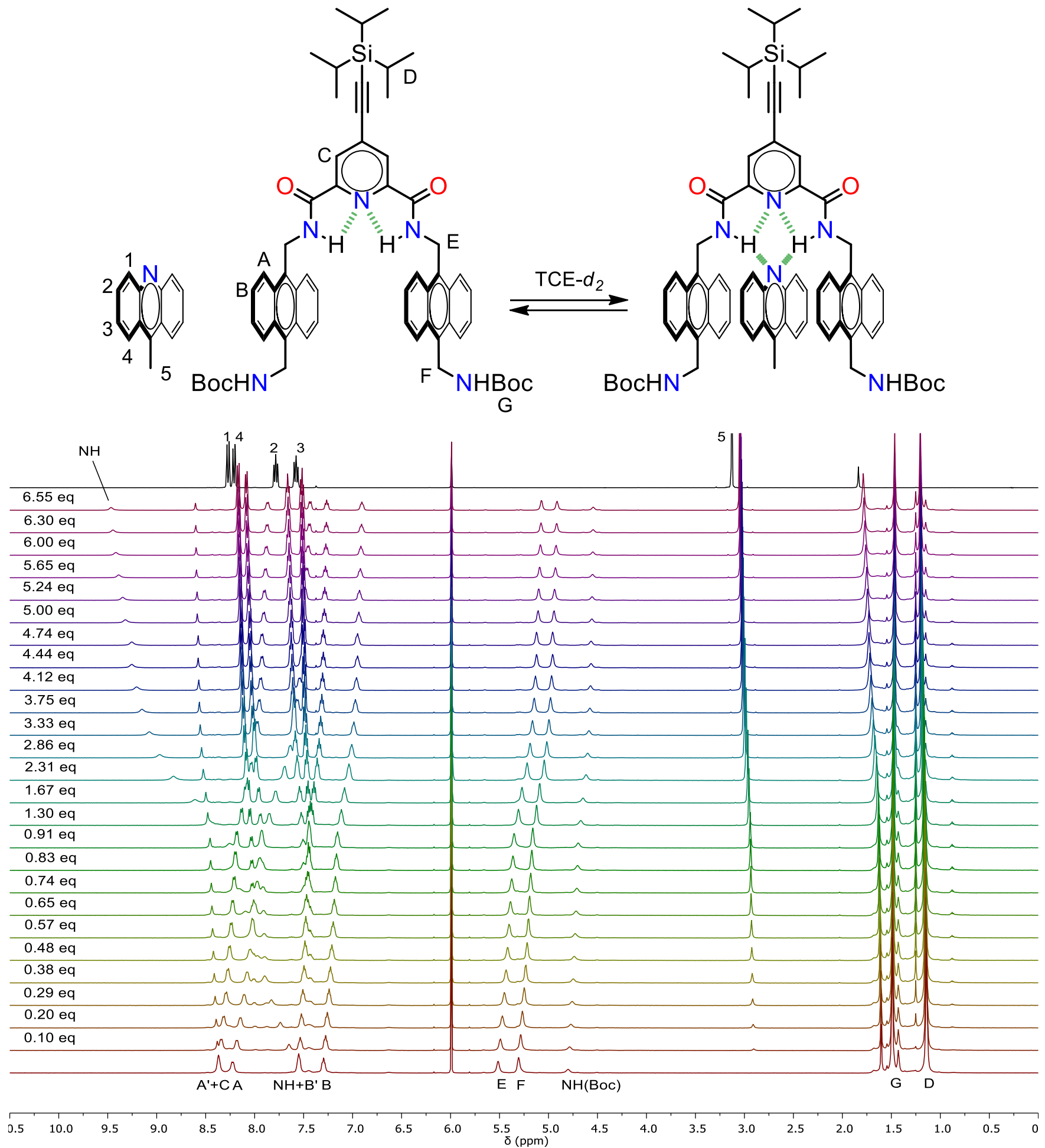

Figure S1. NMR titration of anthracene dimer (A-A) and 9-methylacrdine in TCE- $d_{2}, 500 \mathrm{MHz}, 25^{\circ} \mathrm{C}$ at a constant concentration of A-A of $5 \times 10^{-3}$. Titrant solution is $5 \times 10^{-2} \mathrm{M}$ of 9 -methylacridine in host solution. $\mathrm{K}=139.81 \mathrm{M}^{-1} \pm 1.1983 \%$ is calculated on the variation of chemical shift of protons $\mathbf{B}, \mathbf{C}$, $\mathbf{E}$, and $\mathbf{F}$. 

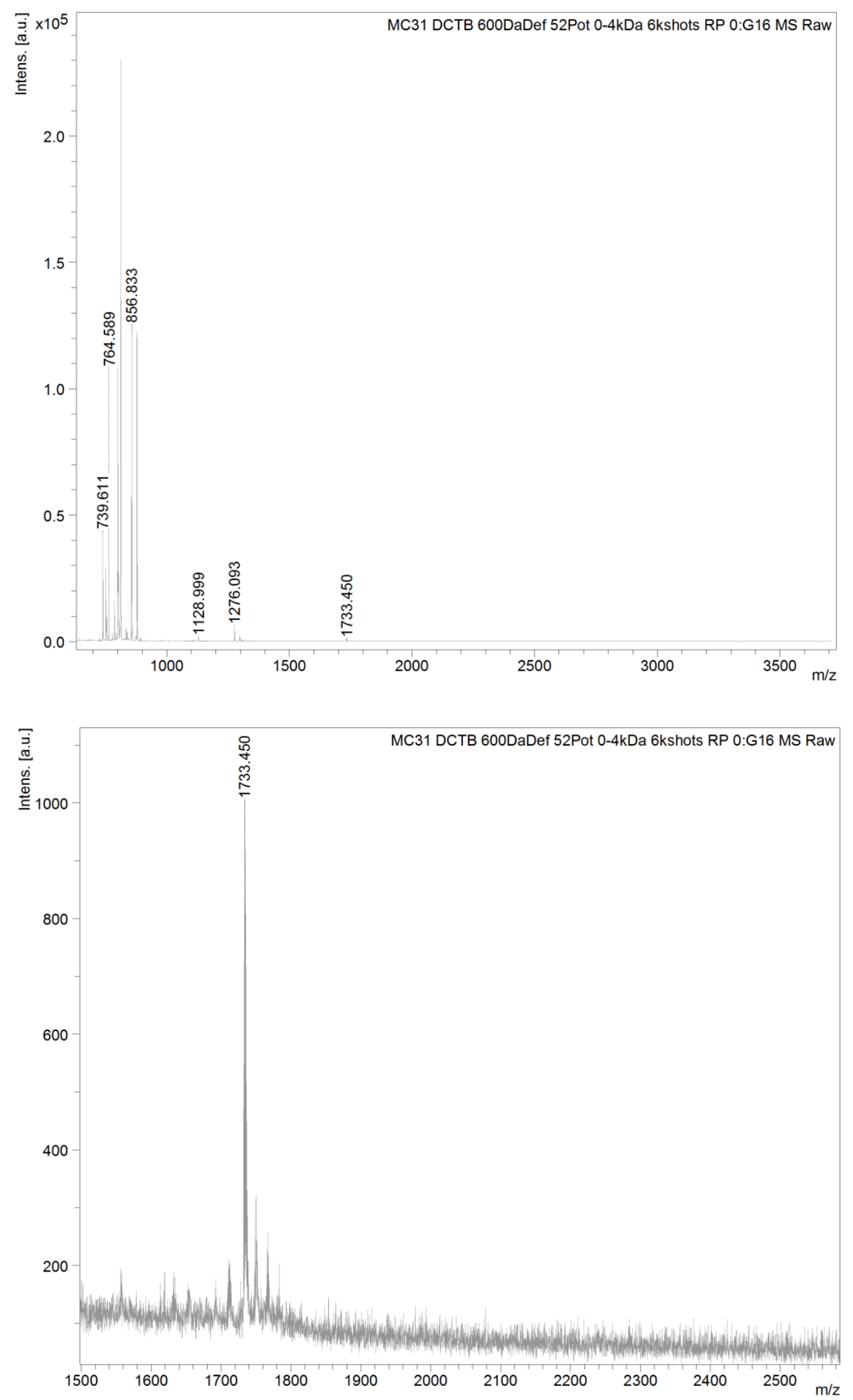

Figure S2. MALDI-TOF of dyad Ac-A. Calculated for $[\mathrm{M}+\mathrm{H}]^{+}:$856.425, found: 856.833; Calculated for [2M+Na] $]^{+}: 1734.829$, found: 1733.450 . 

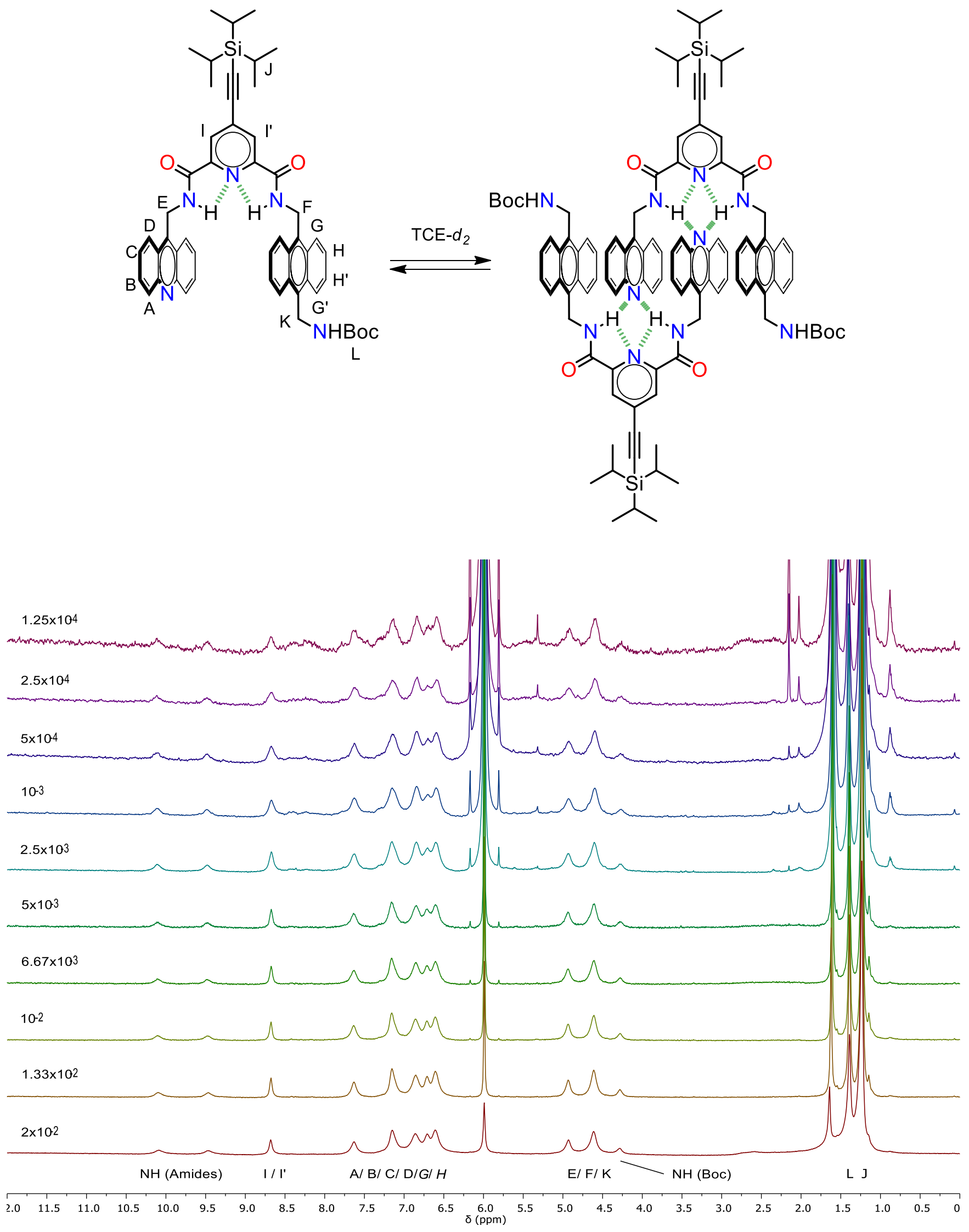

Figure S3. ${ }^{1} \mathrm{H}-\mathrm{NMR}$ dilution experiment of Ac-A (TCE- $d_{2}, 500 \mathrm{MHz}, 25^{\circ} \mathrm{C}$ ) 

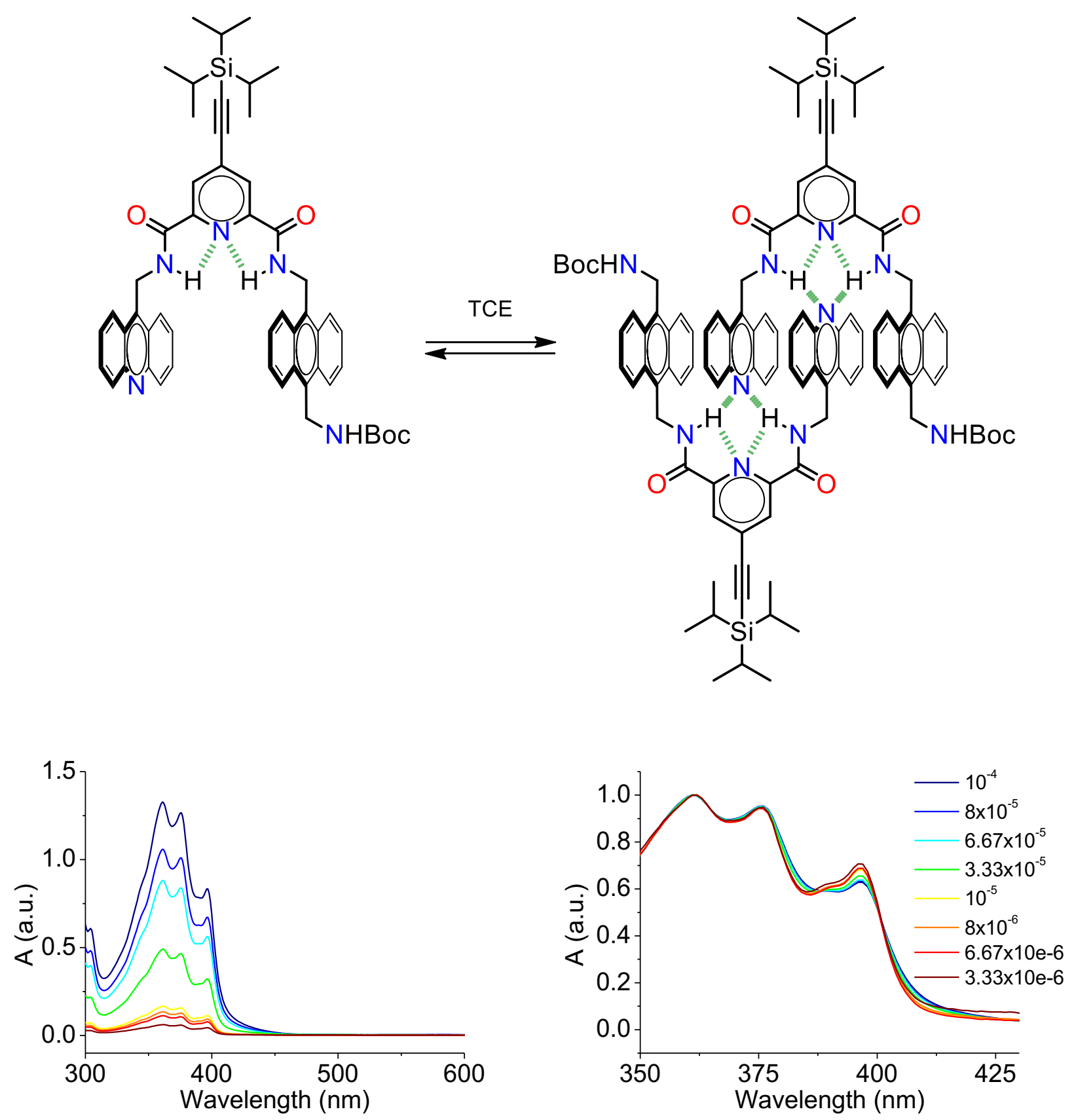

Figure S4. Left: UV-Vis dilution experiment of dyad Ac-A (TCE, $\left.25^{\circ} \mathrm{C}\right)$, Right: normalized at $362 \mathrm{~nm}$ 


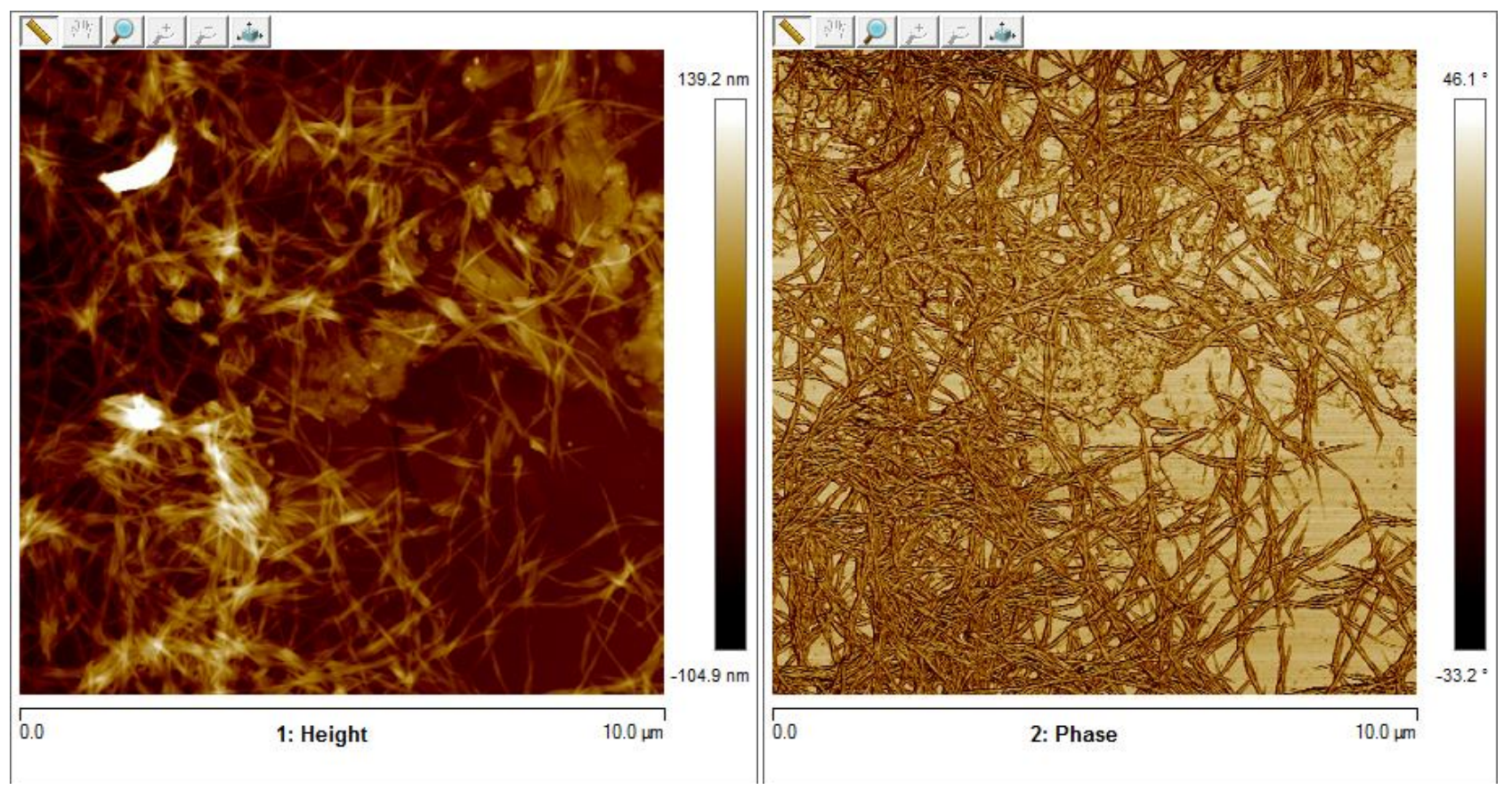

Figure S5. AFM images of polymer Ac-A-Ac: $5 \times 10^{-4} \mathrm{M}$, r.t.

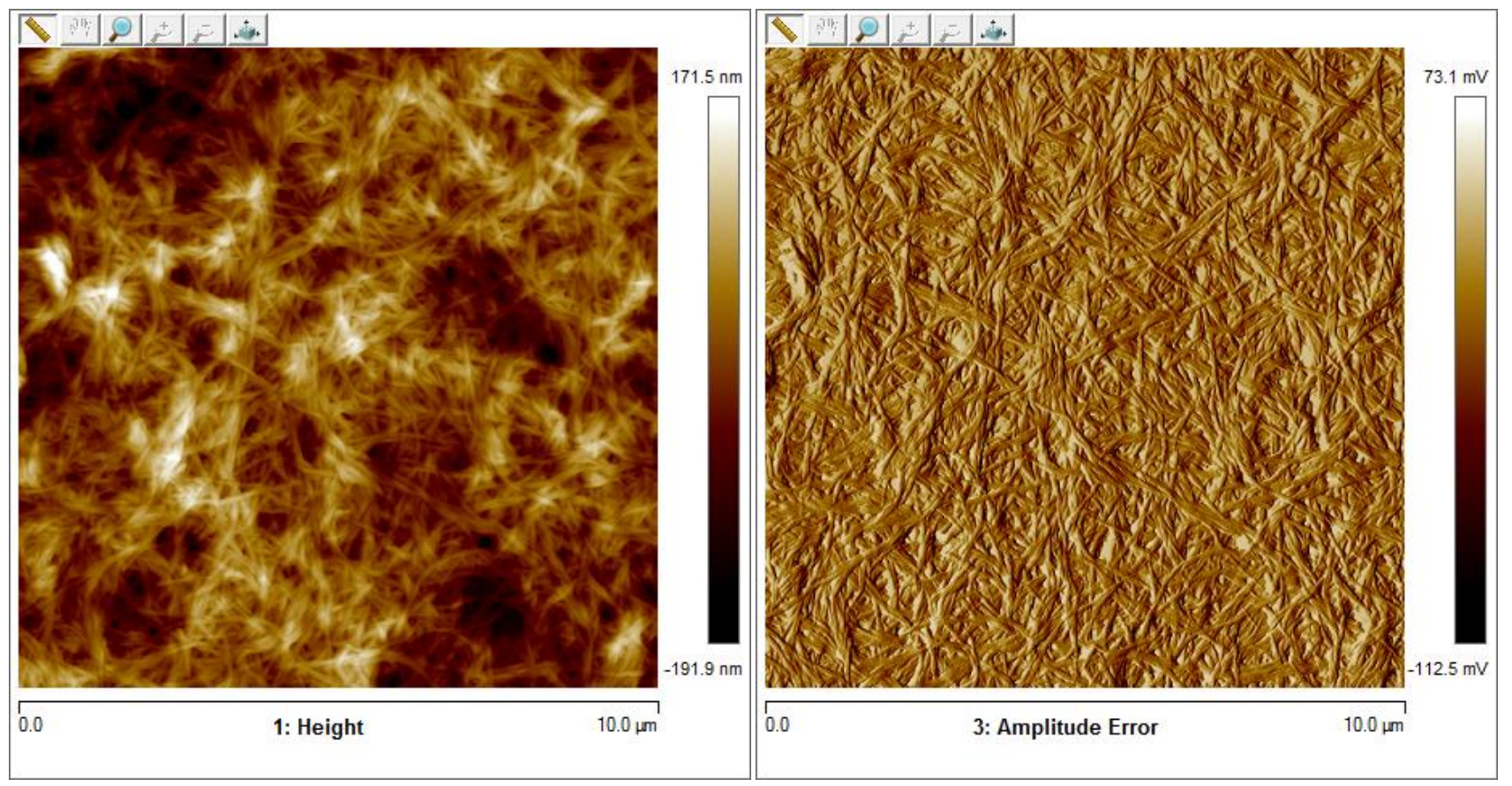

Figure S6. AFM images of polymer Ac-A-Ac: $5 \times 10^{-4} \mathrm{M}$, r.t., annealing on mica surface: $60^{\circ} \mathrm{C}, 15 \mathrm{~min}$. 


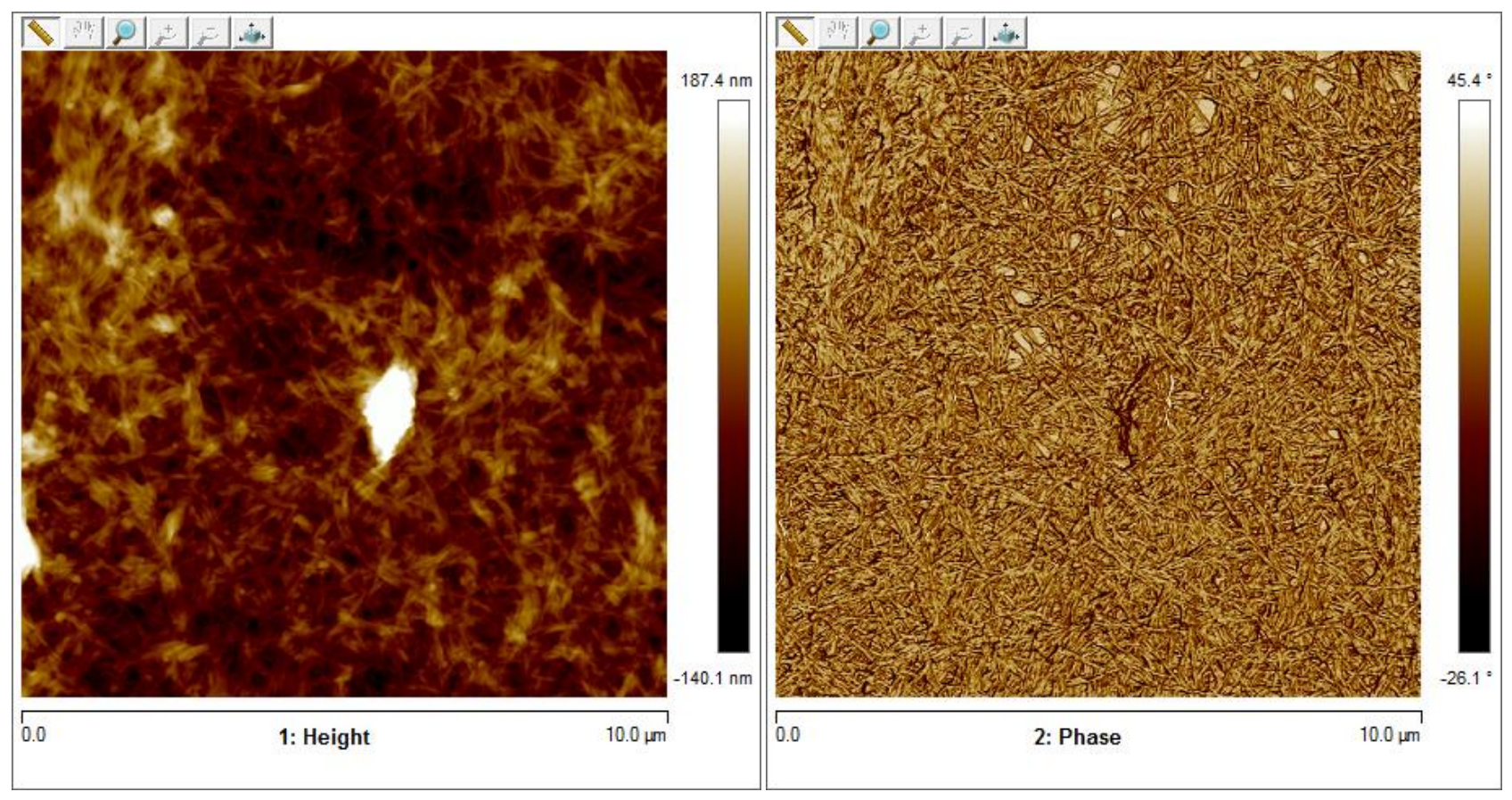

Figure S7. AFM images of polymer Ac-A-Ac: $5 \times 10^{-4} \mathrm{M}, 150^{\circ} \mathrm{C} \rightarrow$ r.t.
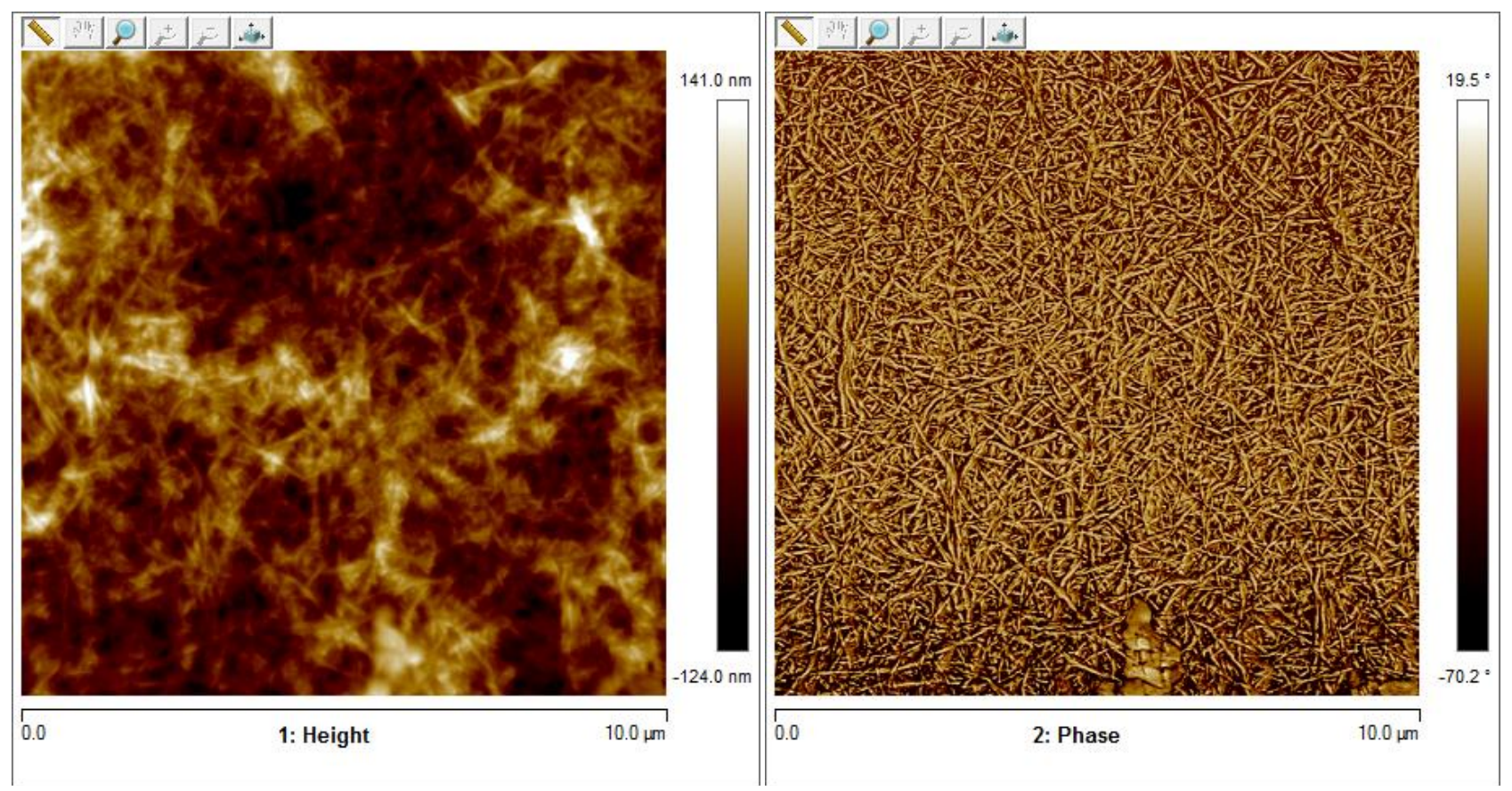

Figure S8. AFM images of polymer Ac-A-Ac: $5 \times 10^{-5} \mathrm{M}$, r.t. 


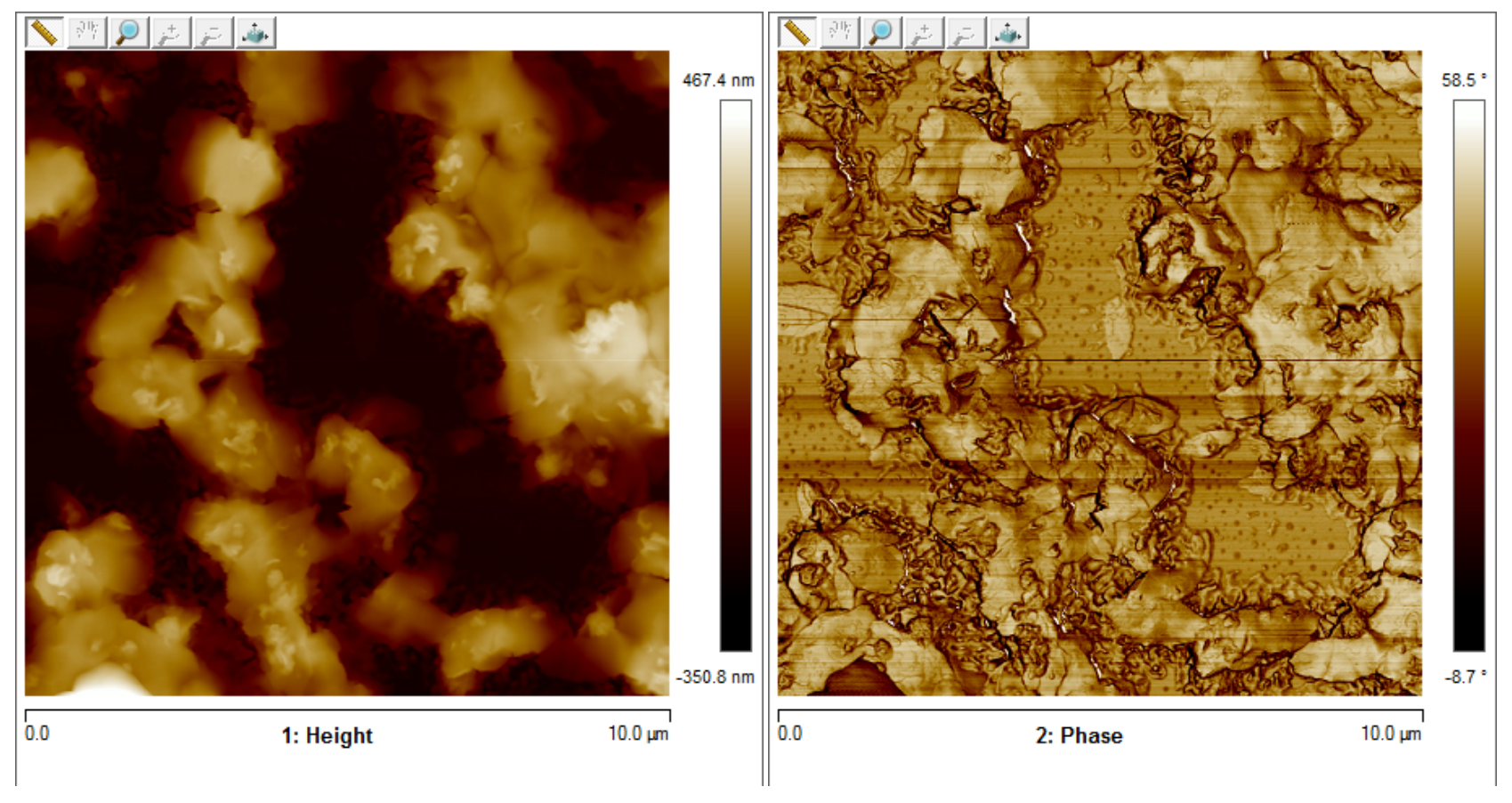

Figure S9. AFM images of compound Ac-A: $5 \times 10^{-4} \mathrm{M}$, r.t. 

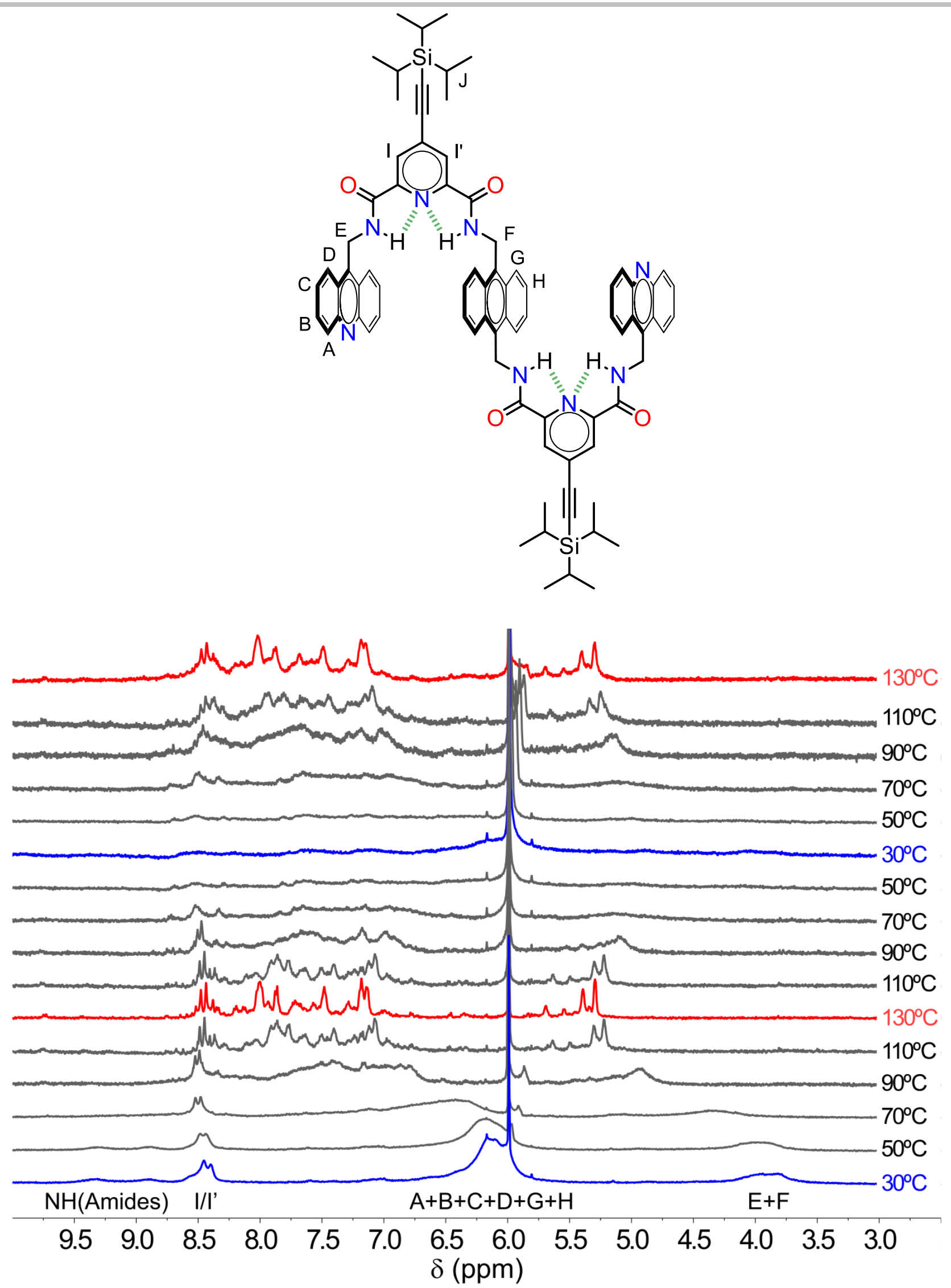

Figure S10. Variable Temperature ${ }^{1} \mathrm{H}-\mathrm{NMR}$ in TCE- $d_{2}$ of Ac-A-Ac, $\left(4 \times 10^{-3} \mathrm{M}\right)$ from bottom to top: heating-cooling-heating. 

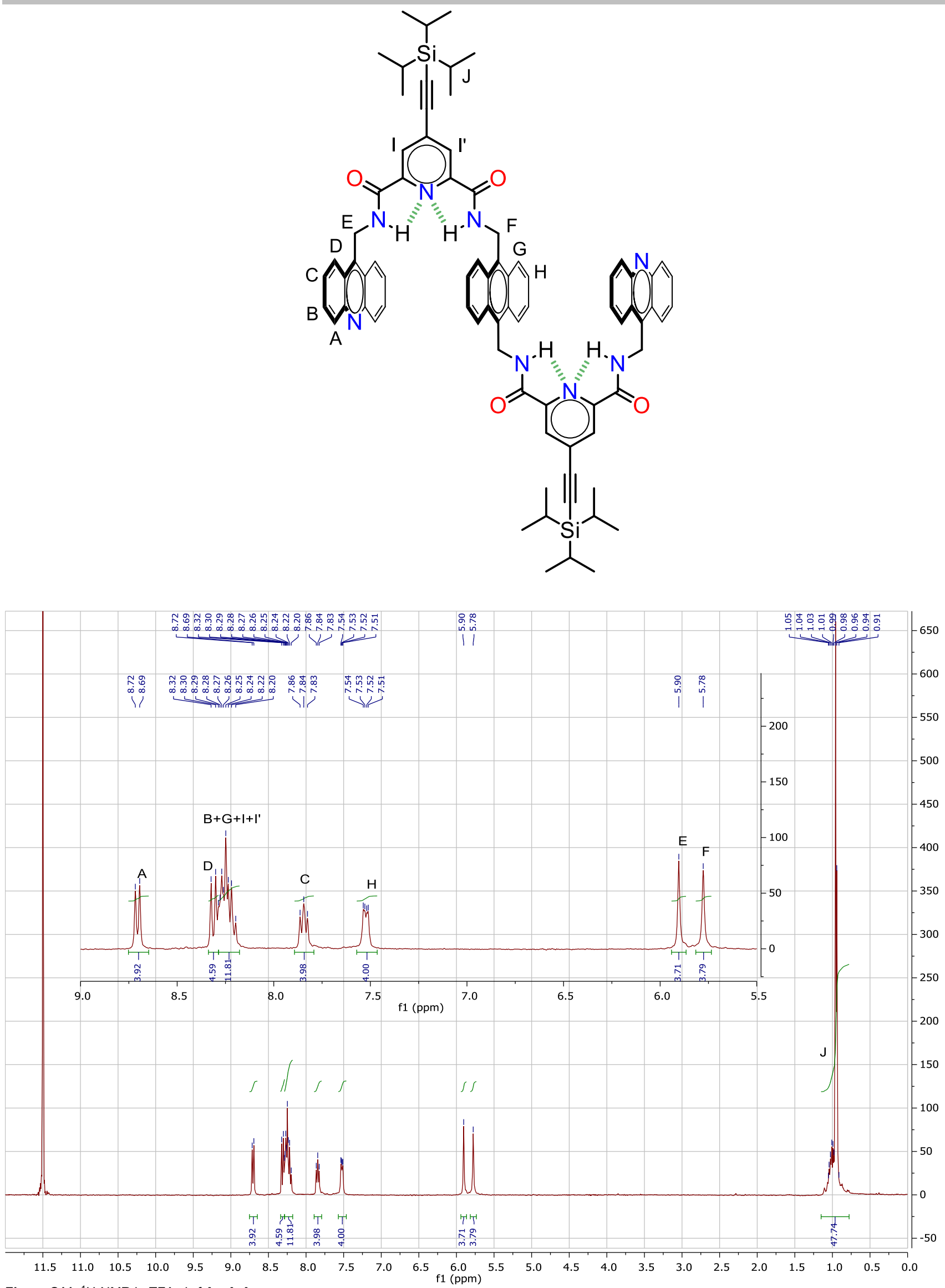

Figure S11. ${ }^{1} \mathrm{H}-\mathrm{NMR}$ in TFA- $d$ of Ac-A-Ac. 

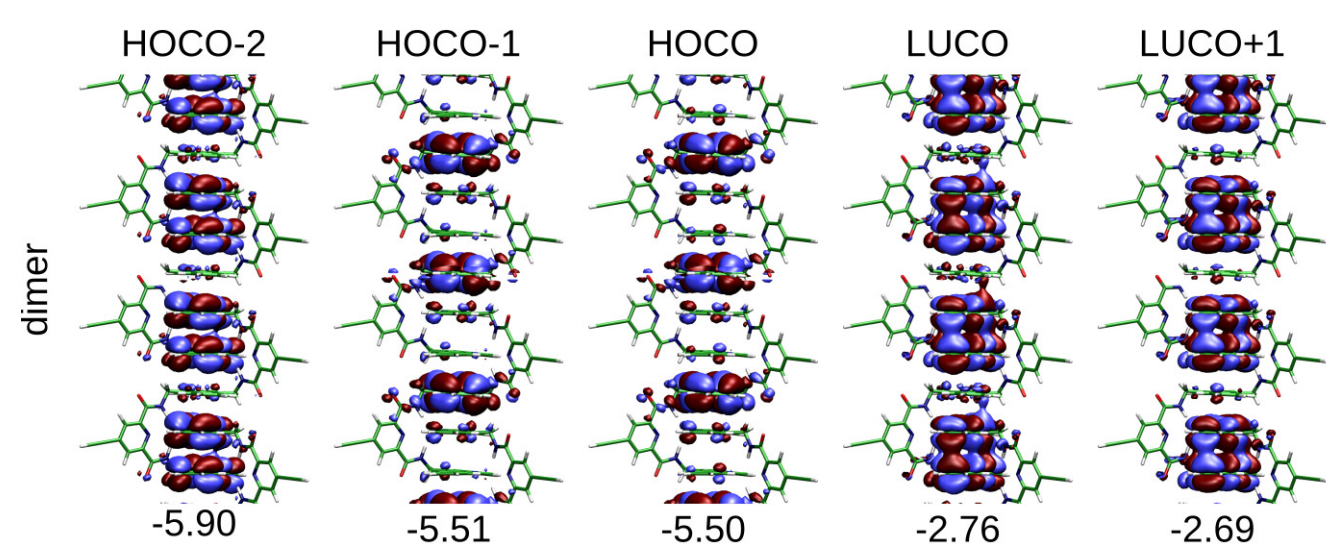

LUCO+2
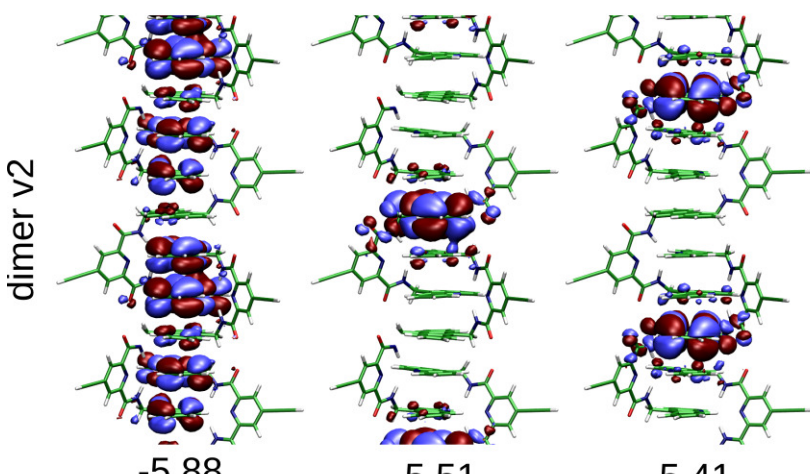

$-541$
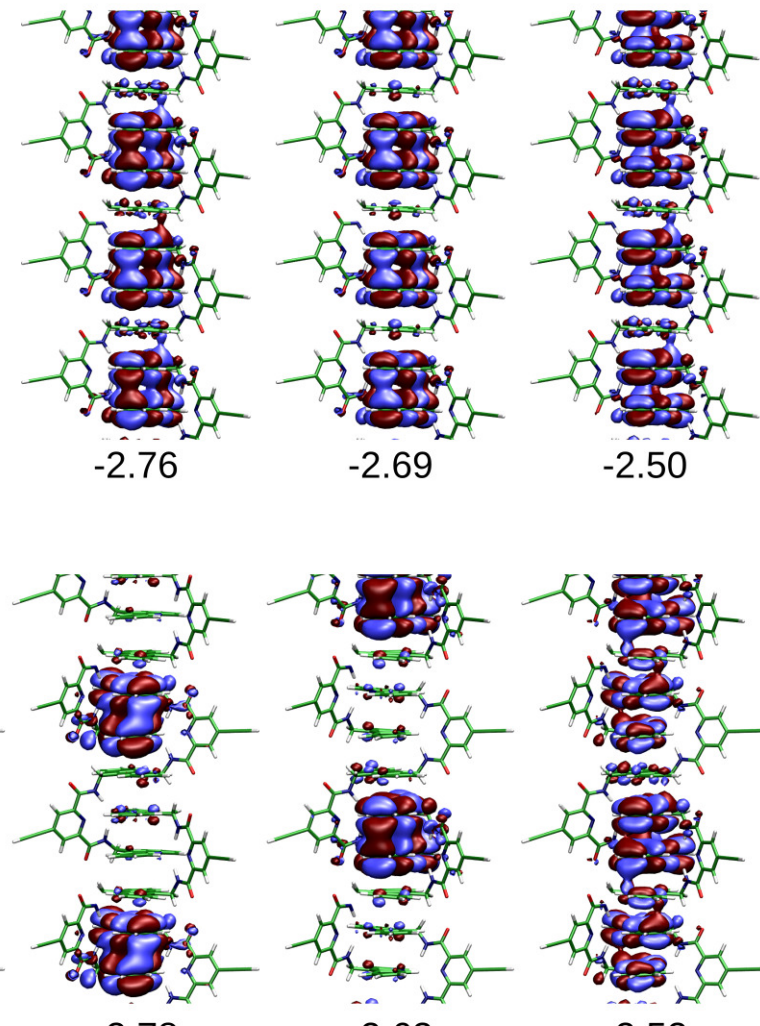

Figure S12. Frontier orbital of two optimized unit cells with two monomers with similar (top) and different (bottom) relative orientations at the B3LYP/light // PBEMBD/light level. 


\section{Materials and Methods}

Commercial chemicals and solvents were used as received. Tetrahydrofuran was dried using an Innovative Pure Solve solvent purification system. Analytical thin layer chromatography (TLC) was carried out using aluminum sheets $(20 \times 20 \mathrm{~cm})$ pre-coated with silica gel RP-18W 60 F254 from Merck. Column chromatography was carried out using Silica gel $60(40-60 \mu \mathrm{m})$ from Scharlab.

NMR spectra in solution were recorded on a Bruker Avance $400 \mathrm{MHz}$ or $500 \mathrm{MHz}$ spectrometer at $298 \mathrm{~K}$ using partially deuterated solvents as internal standards.

Matrix Assisted Laser Desorption Ionization (coupled to a Time-Of-Flight analyzer) experiments MALDI-TOF) were recorded on Bruker REFLEX spectrometer by Dr. Antonio Veloso at POLYMAT.

Absorption spectra were recorded on a Perkin-Elmer Lambda 950 spectrometer.

AFM was recorded on a AFM Dimension ICON (Bruker) (Tapping mode, Tips: Tesp-v2 (Spring Const.: $37 \mathrm{~N} / \mathrm{m}$, Resonant Freq.: 320 khz) by Dr. María Dolores Martín Alberdi at the University of the Basque Country. AFM samples were prepared by dissolving $/$ suspending Ac-A-Ac in tetrachloroethane at the concentration and temperature indicated below. 2 drops were deposited on a mica surface and left to evaporate. There is no significant effect of concentration and temperature on the morphology of the fibers.

SEM was recorded on a FEI HELIOS 450 S by Dr. Evgenii Modin at CIC NanoGUNE.

Time-resolved microwave conductivity (TRMC). A film on a quartz substrate was set in a resonant cavity and probed by continuous microwaves at $\sim 9.1 \mathrm{GHz}$. The third harmonic generation (THG; $355 \mathrm{~nm}$ ) of an Nd:YAG laser (Continuum Inc., Surelite II, 5-8 ns pulse duration, $10 \mathrm{~Hz}$ ) was used as an excitation source (incident photon density, $l_{0}=9.1 \times 10^{15}$ photons $\mathrm{cm}^{-2} \mathrm{pulse}^{-1}$ ). The photoconductivity transient $\Delta \sigma$ was converted to the product of the quantum yield $(\varphi)$ and the sum of the charge carrier mobilities, $\Sigma \mu$ $\left(=\mu_{\mathrm{h}}+\mu_{\mathrm{e}}\right)$ by $\varphi \Sigma \mu=\Delta \sigma\left(e l_{0} F_{\text {light }}\right)^{-1}$, where $e$ and $F_{\text {light }}$ are the unit charge of a single electron and the correction (or filling) factor, respectively. 


\section{Synthesis}
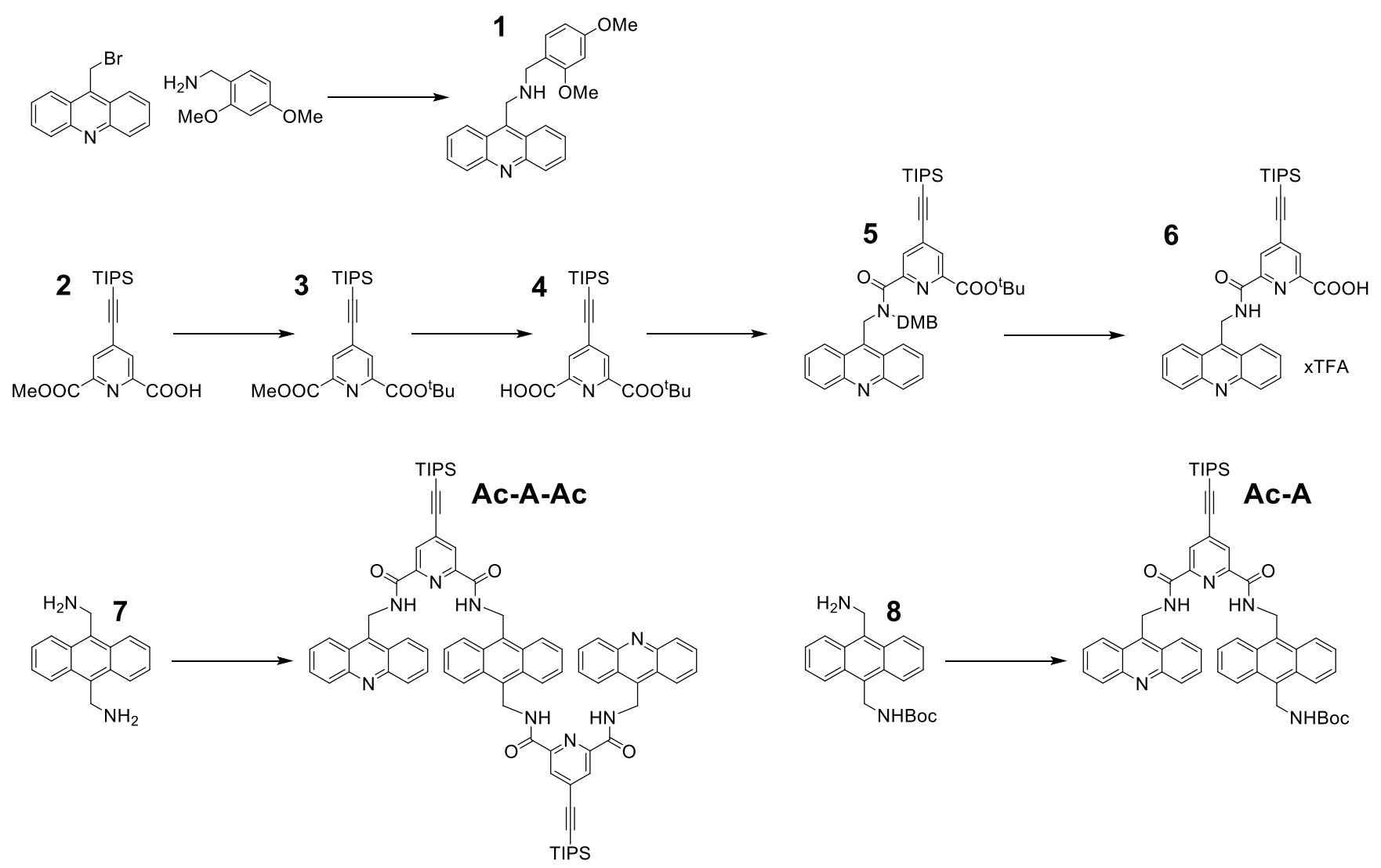

Scheme S1. Compounds 2, 7, 8 and Anthracene dimer A-A were synthesized according to the literature. ${ }^{[1]}$ 
<smiles>BrCc1c2ccccc2nc2ccccc12</smiles><smiles>COc1ccc(CN)c(OC)c1</smiles>

1. DIEA, $\mathrm{CHCl}_{3}$ $0^{\circ} \mathrm{C} \rightarrow$ r.t.

2. $\mathrm{HCl}, \mathrm{Et}_{2} \mathrm{O}$<smiles>COc1cc(I)c(CNCc2c3ccccc3nc3ccccc23)c(OC)c1</smiles>

$331 \mu \mathrm{l}$ of 2,4-dimethoxybenzylamine $(2.205 \mathrm{mmol})$ and $384 \mu \mathrm{l}$ of diisopropylethylamine $(2.205 \mathrm{mmol})$ were dissolved in $6 \mathrm{ml}$ of chloroform. $300 \mathrm{mg}$ of 9 -(bromomethyl)acridine $(1.102 \mathrm{mmol})$ were added dropwise at $0^{\circ} \mathrm{C}$ in $15 \mathrm{ml}$ of chloroform during 1 hour. The reaction was stirred at r.t. for 4 hours and the solvent removed under reduced pressure. The product was purified by column chromatography in $\mathrm{CHCl}_{3} \rightarrow \mathrm{CHCl}_{3} / \mathrm{MeOH}$ 99:1. The residue was dissolved in few $\mathrm{ml} \mathrm{of} \mathrm{Et}_{2} \mathrm{O}$ and $\mathrm{HCl}$ saturated solution in $\mathrm{Et}_{2} \mathrm{O}$ was added with stirring. The hydrochloride salt precipitates as a yellow-orange solid, that was filtered and washed with $\mathrm{Et}_{2} \mathrm{O}$.

$353.2 \mathrm{mg}(0.819 \mathrm{mmol})$ obtained. $74 \%$

The product was stored at $-18^{\circ} \mathrm{C}$ and used within few days without further purification.

${ }^{1} \mathrm{H}$ NMR $(400 \mathrm{MHz}$, DMSO-d 6 ) $\delta 9.53(\mathrm{~s}, 2 \mathrm{H}), 8.56(\mathrm{~d}, J=9.0 \mathrm{~Hz}, 2 \mathrm{H}), 8.44(\mathrm{~d}, J=8.9 \mathrm{~Hz}, 2 \mathrm{H}), 8.12(\mathrm{t}, J=7.6 \mathrm{~Hz}, 2 \mathrm{H}), 7.88(\mathrm{t}, J=$ $7.7 \mathrm{~Hz}, 2 \mathrm{H}), 7.41(\mathrm{~d}, J=8.4 \mathrm{~Hz}, 1 \mathrm{H}), 6.64(\mathrm{~s}, 1 \mathrm{H}), 6.58(\mathrm{~d}, J=8.6 \mathrm{~Hz}, 1 \mathrm{H}), 5.32(\mathrm{~s}, 2 \mathrm{H}), 4.39(\mathrm{~s}, 2 \mathrm{H}), 3.81(\mathrm{~s}, 3 \mathrm{H}), 3.77(\mathrm{~s}, 3 \mathrm{H}), \mathrm{MS}$ (MALDI): $\mathrm{m} / \mathrm{z}$ calcd. for $\mathrm{C}_{23} \mathrm{H}_{23} \mathrm{~N}_{2} \mathrm{O}_{2}[\mathrm{M}+\mathrm{H}]^{+}: 359.175$, found 359.029 .

A ${ }^{13} \mathrm{C}$ NMR could not be recorded since the compound degradates in solution both as free base in $\mathrm{CDCl}_{3}$ and as $\mathrm{HCl}$ salt in DMSO-d $\mathrm{d}_{6}$ 


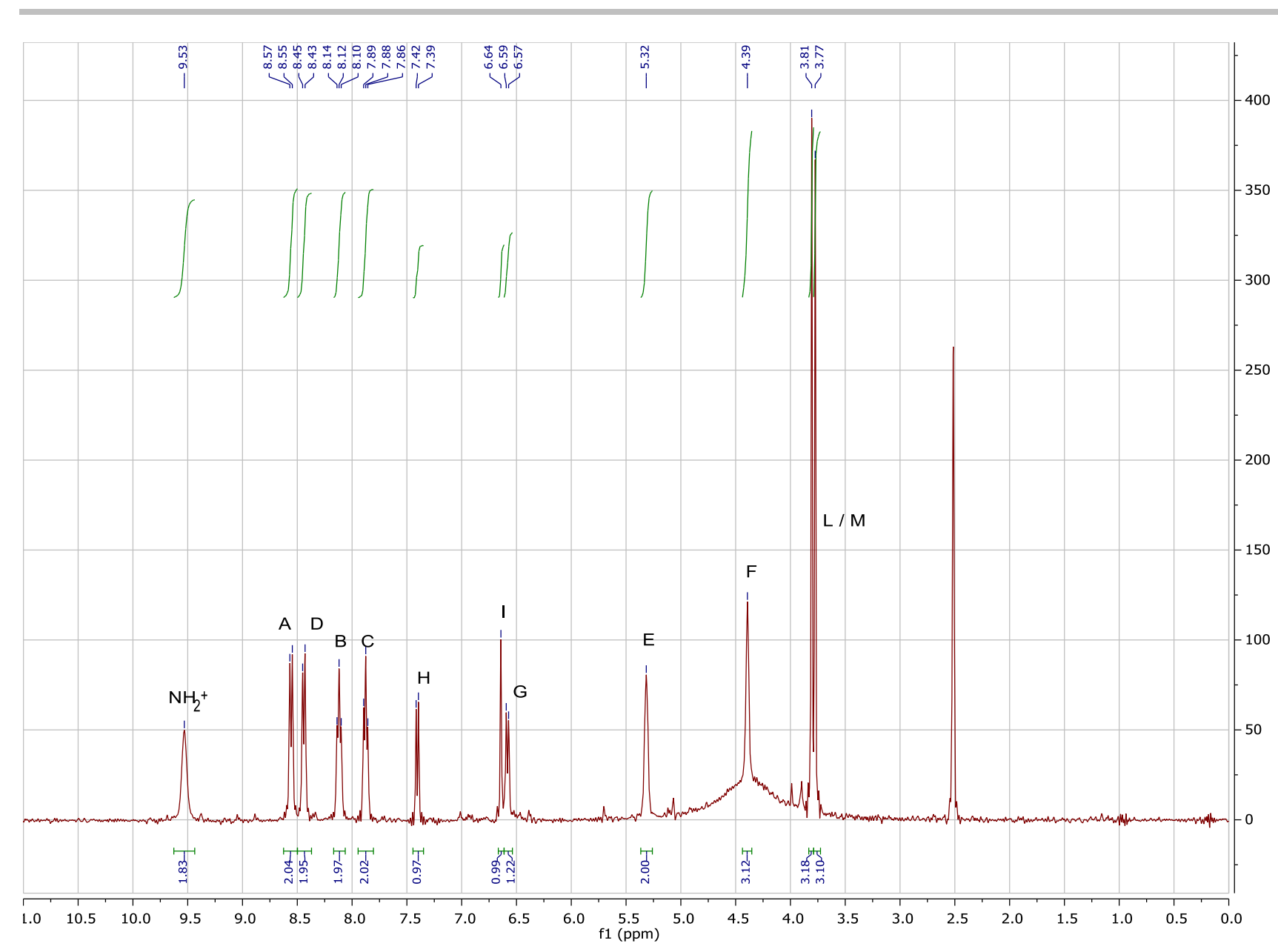

Figure S13. ${ }^{1} \mathrm{H}-\mathrm{NMR}\left(400 \mathrm{MHz}, \mathrm{DMSO}-d_{6}\right)$ of compund 1. 


\section{Synthesis of 3}
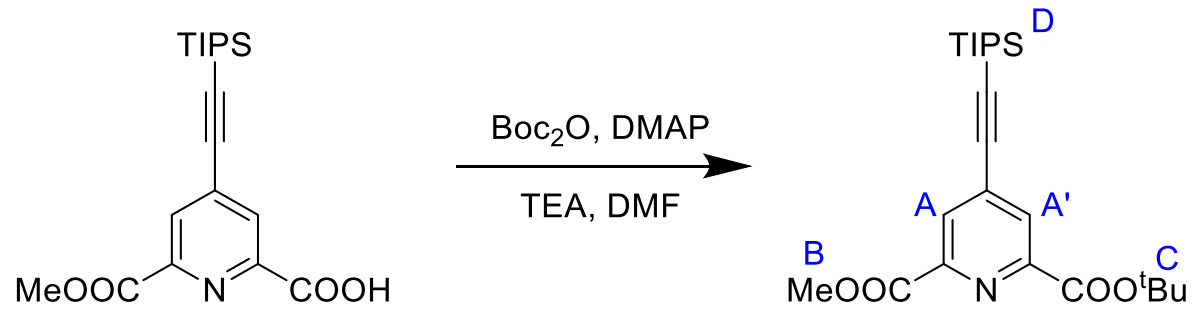

$1.500 \mathrm{~g}$ of $2(4.149 \mathrm{mmol})$ were dissolved in $10 \mathrm{ml}$ of DMF, $50 \mathrm{mg}$ of 4-dimethylaminopyridine $(0.415 \mathrm{mmol})$ and $867 \mu \mathrm{l} \mathrm{of}$ triethylamine were added $(6.224 \mathrm{mmol}), 2.717 \mathrm{~g}$ of $\mathrm{Boc}_{2} \mathrm{O}(12.448 \mathrm{mmol})$ were added in $5 \mathrm{ml}$ of DMF and the reaction was stirred overnight at r.t. Water was added and the product was extracted with Hexane. The product was purified by flash chromatography in Hexane $\rightarrow$ DCM.

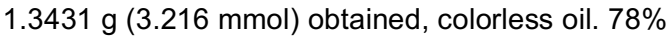

${ }^{1} \mathrm{H}$ NMR $\left(400 \mathrm{MHz}, \mathrm{CDCl}_{3}\right) \delta 8.25(\mathrm{~d}, J=1.4 \mathrm{~Hz}, 1 \mathrm{H}), 8.16(\mathrm{~d}, J=1.5 \mathrm{~Hz}, 1 \mathrm{H}), 4.01(\mathrm{~s}, 3 \mathrm{H}), 1.65(\mathrm{~s}, 9 \mathrm{H}), 1.14(\mathrm{~m}, 21 \mathrm{H}),{ }^{13} \mathrm{C} \mathrm{NMR}$ $\left(101 \mathrm{MHz}, \mathrm{CDCl}_{3}\right) \delta 165.11,162.90,149.88,148.57,134.20,129.79,129.75,102.70,100.21,83.33,53.25,28.17,18.72,11.29, \mathrm{MS}$ (MALDI): $\mathrm{m} / \mathrm{z}$ calcd. for $\mathrm{C}_{23} \mathrm{H}_{35} \mathrm{NO}_{4} \mathrm{SiNa}[\mathrm{M}+\mathrm{Na}]^{+}: 440.223$, found 440.319 . 


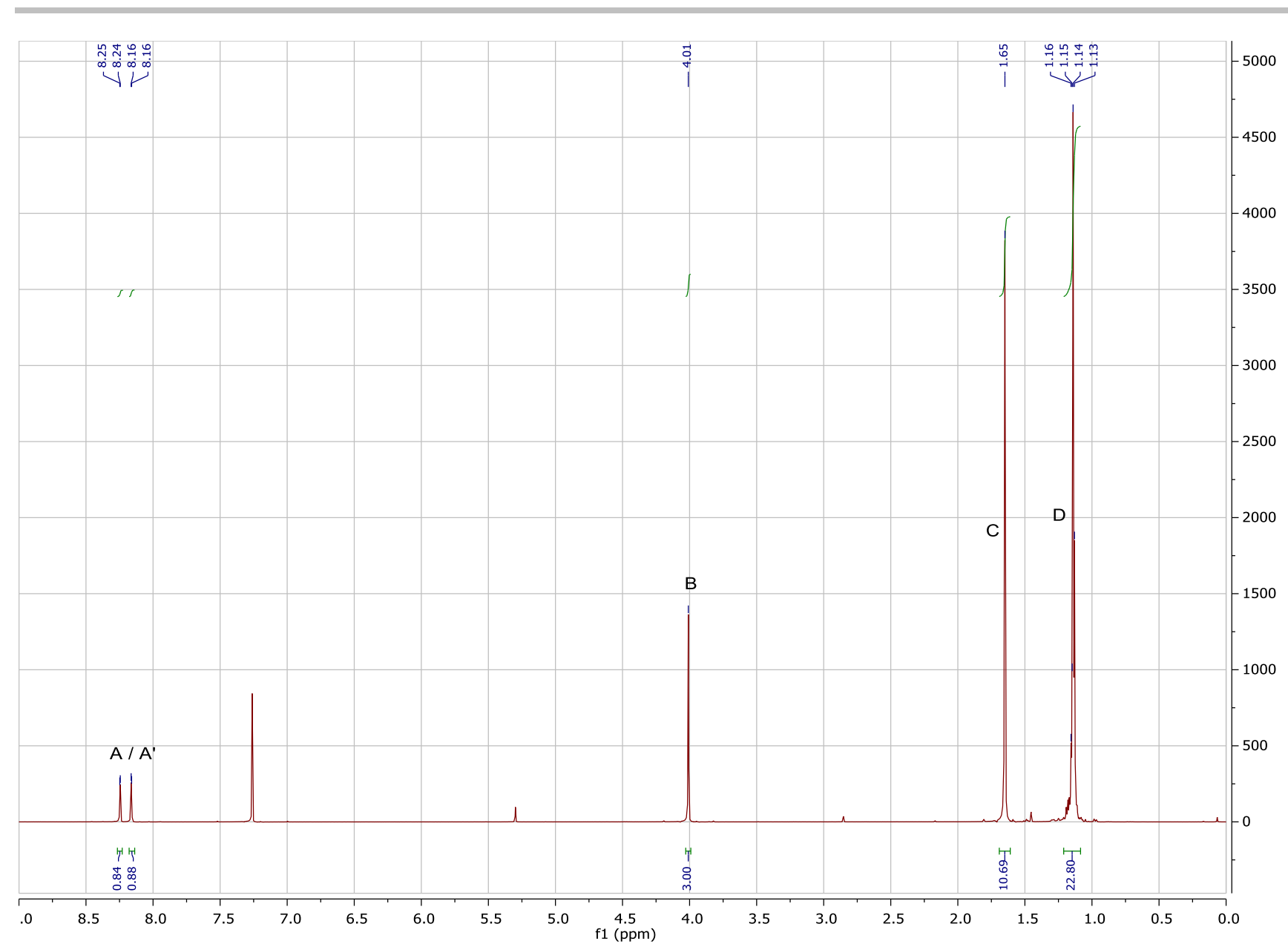

Figure S14. ${ }^{1} \mathrm{H}-\mathrm{NMR}\left(400 \mathrm{MHz}, \mathrm{CDCl}_{3}\right)$ of compund 3. 


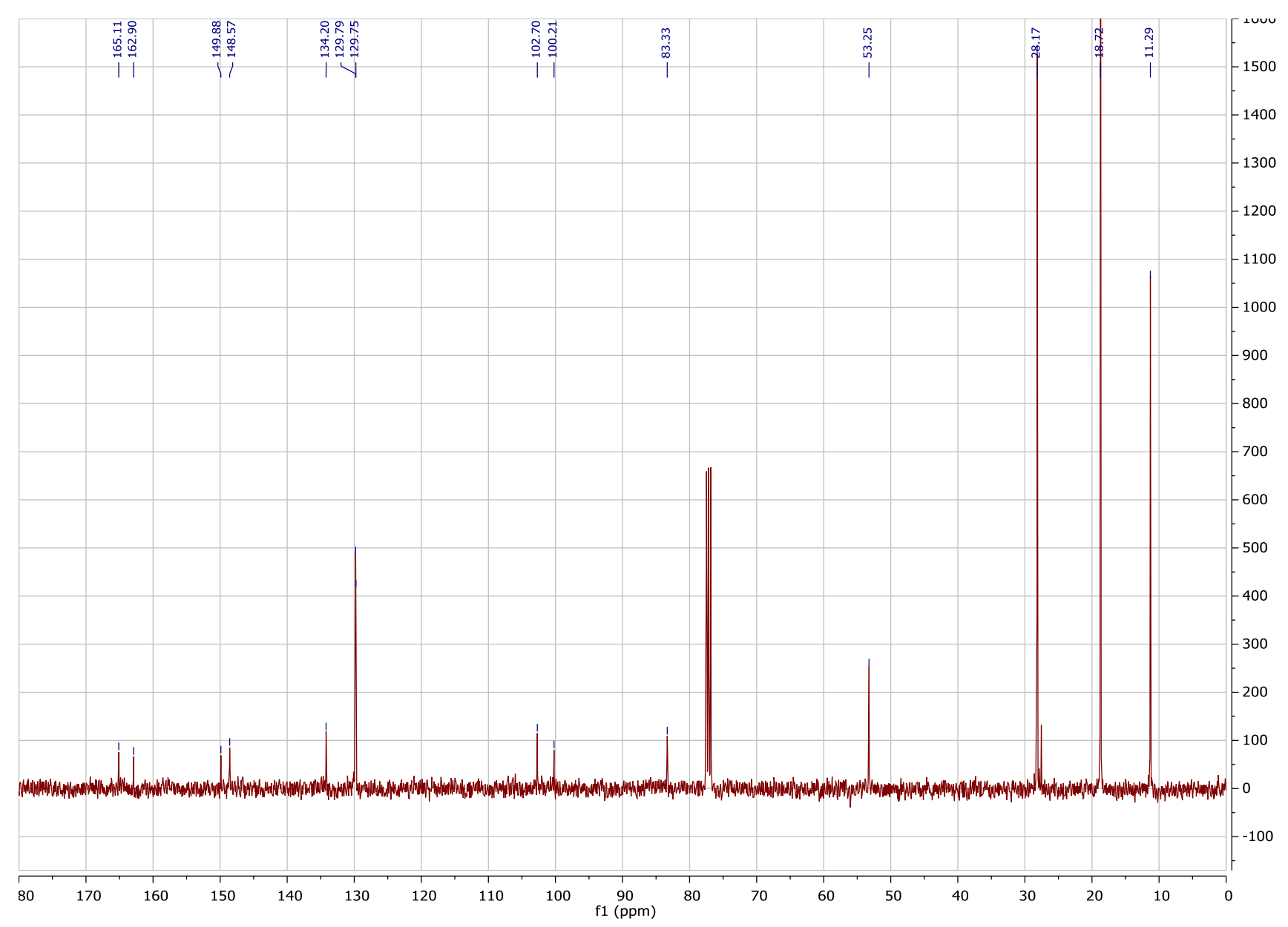

Figure S15. ${ }^{13} \mathrm{C}-\mathrm{NMR}\left(100 \mathrm{MHz}, \mathrm{CDCl}_{3}\right)$ of compund $\mathbf{3}$. 


\section{Synthesis of 4}

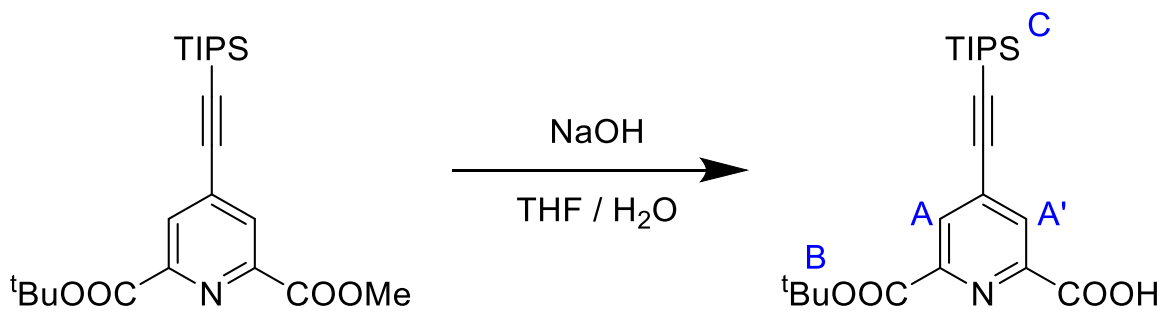

$1.339 \mathrm{~g}$ of $3(3.207 \mathrm{mmol})$ were dissolved in $8 \mathrm{ml}$ of THF and $141 \mathrm{mg}$ of $\mathrm{NaOH}(3.528 \mathrm{mmol})$ were added in $2 \mathrm{ml}$ of water. The reaction was stirred overnight at r.t., diluted with water and $2 \mathrm{M} \mathrm{HCl}$ until $\mathrm{pH} \sim 3$ and extracted with $\mathrm{CHCl}_{3}$. The product was purified by column chormatography in $\mathrm{CHCl}_{3} / \mathrm{MeOH} 95: 5$

$1.0353 \mathrm{~g}(2.565 \mathrm{mmol})$ obtained, colorless oil. $80 \%$

${ }^{1} \mathrm{H}$ NMR (400 MHz, DMSO-d $) \delta 13.71$ (bs, $\left.1 \mathrm{H}\right), 8.10$ (s, 1H), 8.05 (s, 1H), $1.58(\mathrm{~s}, 9 \mathrm{H}), 1.11(\mathrm{~m}, 21 \mathrm{H}),{ }^{13} \mathrm{C}$ NMR $(101 \mathrm{MHz}, \mathrm{DMSO}-$ $\left.\mathrm{d}_{6}\right) \delta 165.00,162.57,149.62,132.25,128.75,128.22,102.83,98.37,82.37,27.60,18.38,10.53$, MS (MALDI): m/z calcd. for $\mathrm{C}_{22} \mathrm{H}_{33} \mathrm{NO}_{4} \mathrm{SiNa}[\mathrm{M}+\mathrm{Na}]^{+}:$426.207, found 426.243 . 


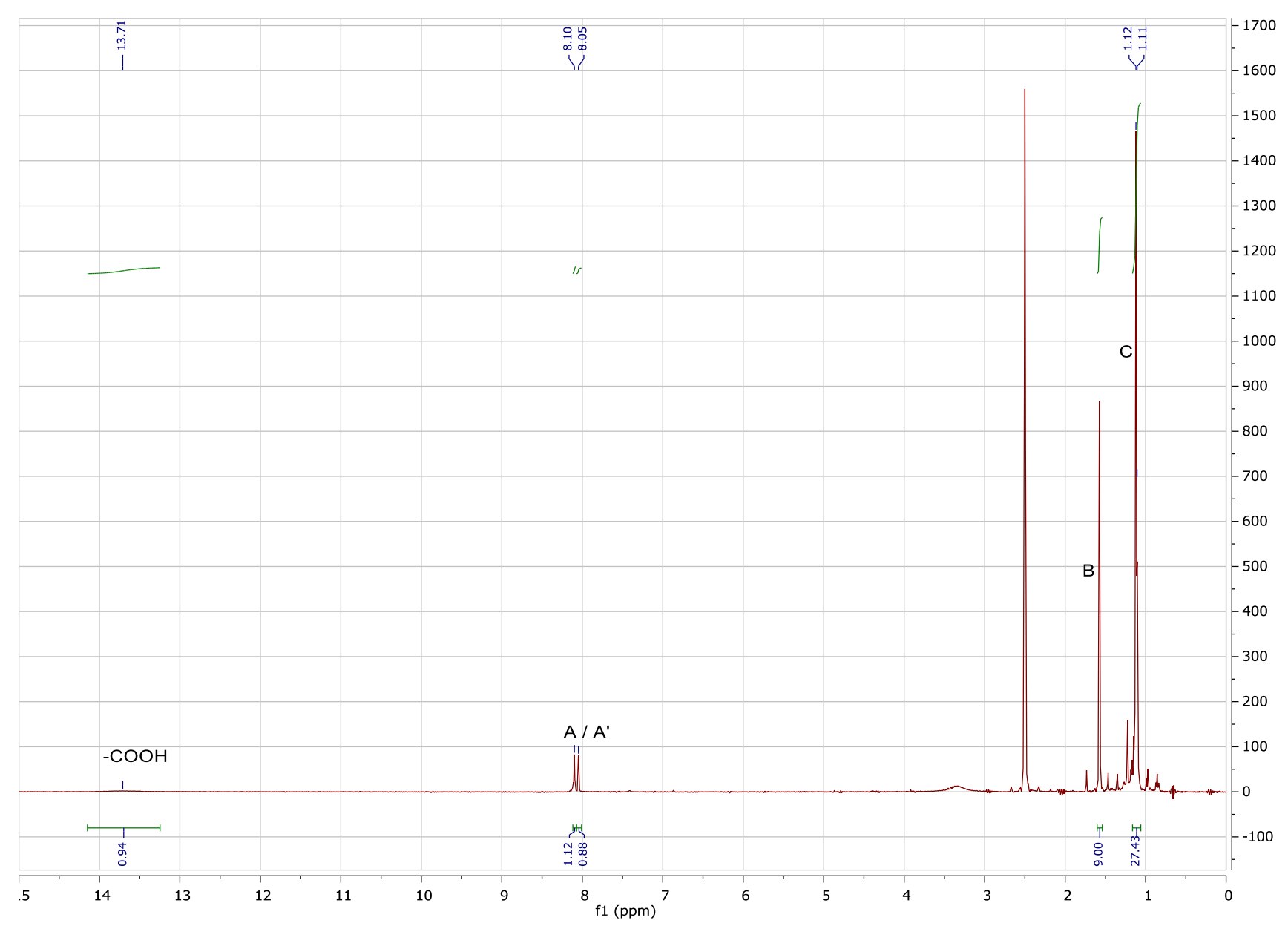

Figure S16. ${ }^{1} \mathrm{H}-\mathrm{NMR}\left(400 \mathrm{MHz}\right.$, DMSO- $\left.d_{6}\right)$ of compund 4. 


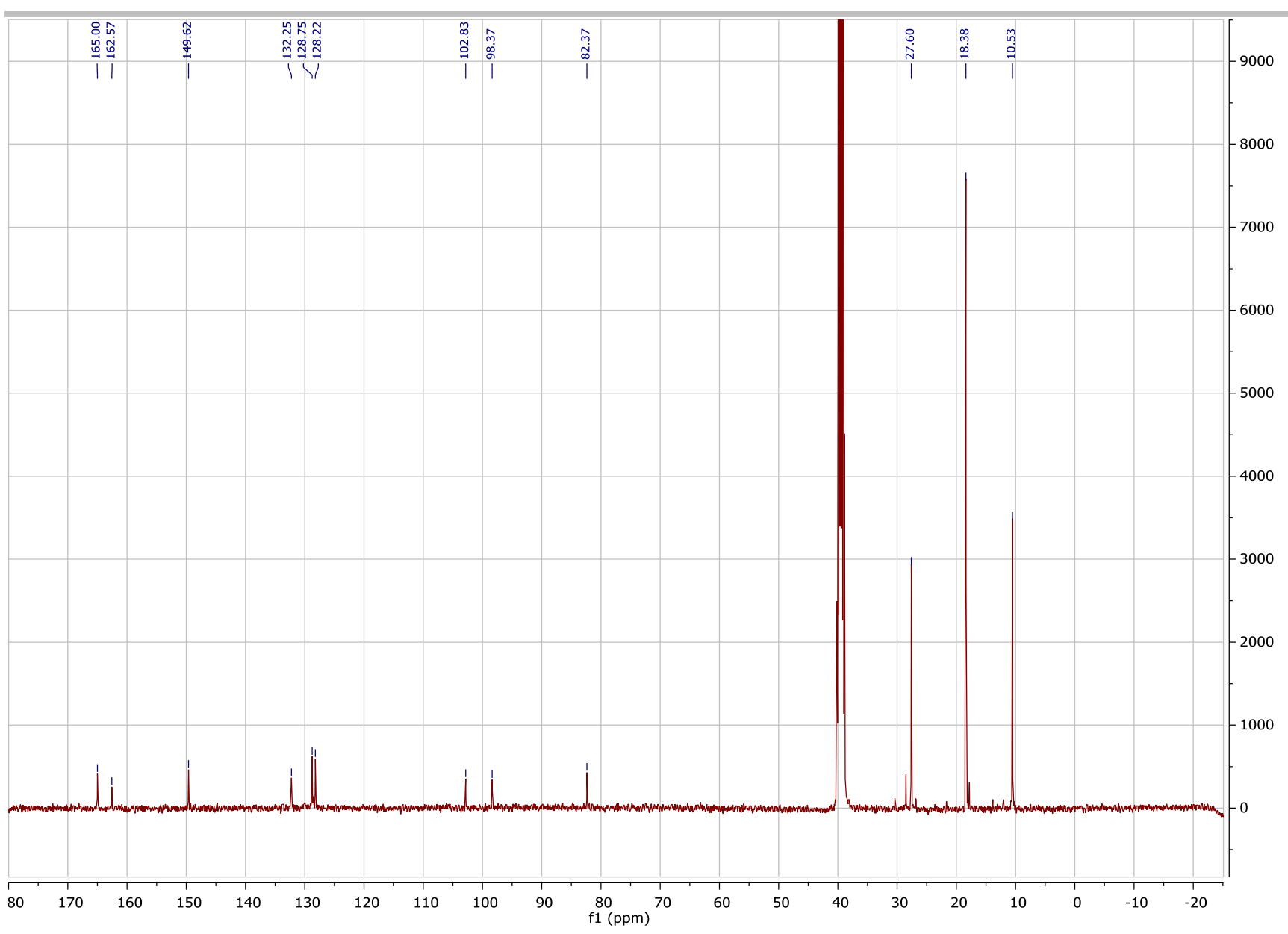

Figure S17. ${ }^{13} \mathrm{C}-\mathrm{NMR}\left(100 \mathrm{MHz}\right.$, DMSO- $\left.d_{6}\right)$ of compund 4. 
<smiles>CCCCOC(=O)c1cc(C#C[InH])cc(C(=O)O)n1</smiles>

1. $(\mathrm{COCl})_{2}$ cat. DMF $\mathrm{CHCl}_{3}, \mathrm{~N}_{2}, 0^{\circ} \mathrm{C}->$ r.t.

2.<smiles>CCNCc1c2ccccc2nc2ccccc12</smiles>

TEA, $\mathrm{CHCl}_{3}, \mathrm{~N}_{2}, 0^{\circ} \mathrm{C}->$ r.t.<smiles>COc1ccc(CN(Cc2c3ccccc3nc3ccccc23)C(=O)c2cc(C#CC(=O)[SnH])cc(C(=O)O[R5](F)(F)F)n2)c(OC)c1</smiles>

$300 \mathrm{mg}$ of $4(0.743 \mathrm{mmol})$ were dissolved in $3 \mathrm{ml}$ of dry DCM under $\mathrm{N}_{2}$ atmosphere and $319 \mu \mathrm{l}$ of oxalyl chloride (3.717 mmol) were added at $0^{\circ} \mathrm{C}$, followed by 2 drops of dry DMF. The solution was left to warm to r.t. and was stirred for 2 hours, then the solvent was removed under reduced pressure and the acid chloride was vacuum-dried for $30 \mathrm{~min}$. The residue was dissolved in $3 \mathrm{ml}$ of dry chloroform under $\mathrm{N}_{2}$ atmosphere and a solution of $353 \mathrm{mg}$ of $3(0.818 \mathrm{mmol})$ and $518 \mu \mathrm{l}$ of triethylamine $(3.717 \mathrm{mmol})$ in $3 \mathrm{ml}$ of dry chloroform were added at $0^{\circ} \mathrm{C}$. The mixture was stirred for $1 \mathrm{~h} 30^{\prime}$ at r.t. The product was purified by column chromatography in chloroform.

$426.0 \mathrm{mg}(0.573 \mathrm{mmol})$ obtained, off-white solid. $77 \%$

${ }^{1} \mathrm{H}$ NMR $\left(400 \mathrm{MHz}, \mathrm{CDCl}_{3}\right) \delta 8.25(\mathrm{~d}, J=8.7 \mathrm{~Hz}, 2 \mathrm{H}), 8.11(\mathrm{~d}, J=9.0 \mathrm{~Hz}, 2 \mathrm{H}), 7.98(\mathrm{~s}, 1 \mathrm{H}), 7.87(\mathrm{~s}, 1 \mathrm{H}), 7.76(\mathrm{t}, J=7.7 \mathrm{~Hz}, 2 \mathrm{H}), 7.48$ (t, $J=7.7 \mathrm{~Hz}, 2 \mathrm{H}), 6.93(\mathrm{~d}, J=8.4 \mathrm{~Hz}, 1 \mathrm{H}), 6.26(\mathrm{~d}, J=8.4 \mathrm{~Hz}, 1 \mathrm{H}), 6.06(\mathrm{~s}, 1 \mathrm{H}), 5.81(\mathrm{~s}, 2 \mathrm{H}), 4.30(\mathrm{~s}, 2 \mathrm{H}), 3.76(\mathrm{~s}, 3 \mathrm{H}), 3.16(\mathrm{~s}, 3 \mathrm{H})$, $1.47(\mathrm{~s}, 9 \mathrm{H}), 1.13(\mathrm{~d}, J=4.2 \mathrm{~Hz}, 21 \mathrm{H}),{ }^{13} \mathrm{C} \mathrm{NMR}\left(101 \mathrm{MHz}, \mathrm{CDCl}_{3}\right) \delta 168.52,163.58,160.42,157.97,154.50,148.70,133.67$, $130.11,129.45,128.54,127.40,126.29,124.64,116.49,104.09,103.11,98.09,82.55,55.53,54.51,45.48,39.77,28.08,18.74$, 11.32, MS (MALDI): $\mathrm{m} / \mathrm{z}$ calcd. for $\mathrm{C}_{45} \mathrm{H}_{54} \mathrm{~N}_{3} \mathrm{O}_{5} \mathrm{Si}[\mathrm{M}+\mathrm{H}]^{+}:$744.382, found 744.640 . 


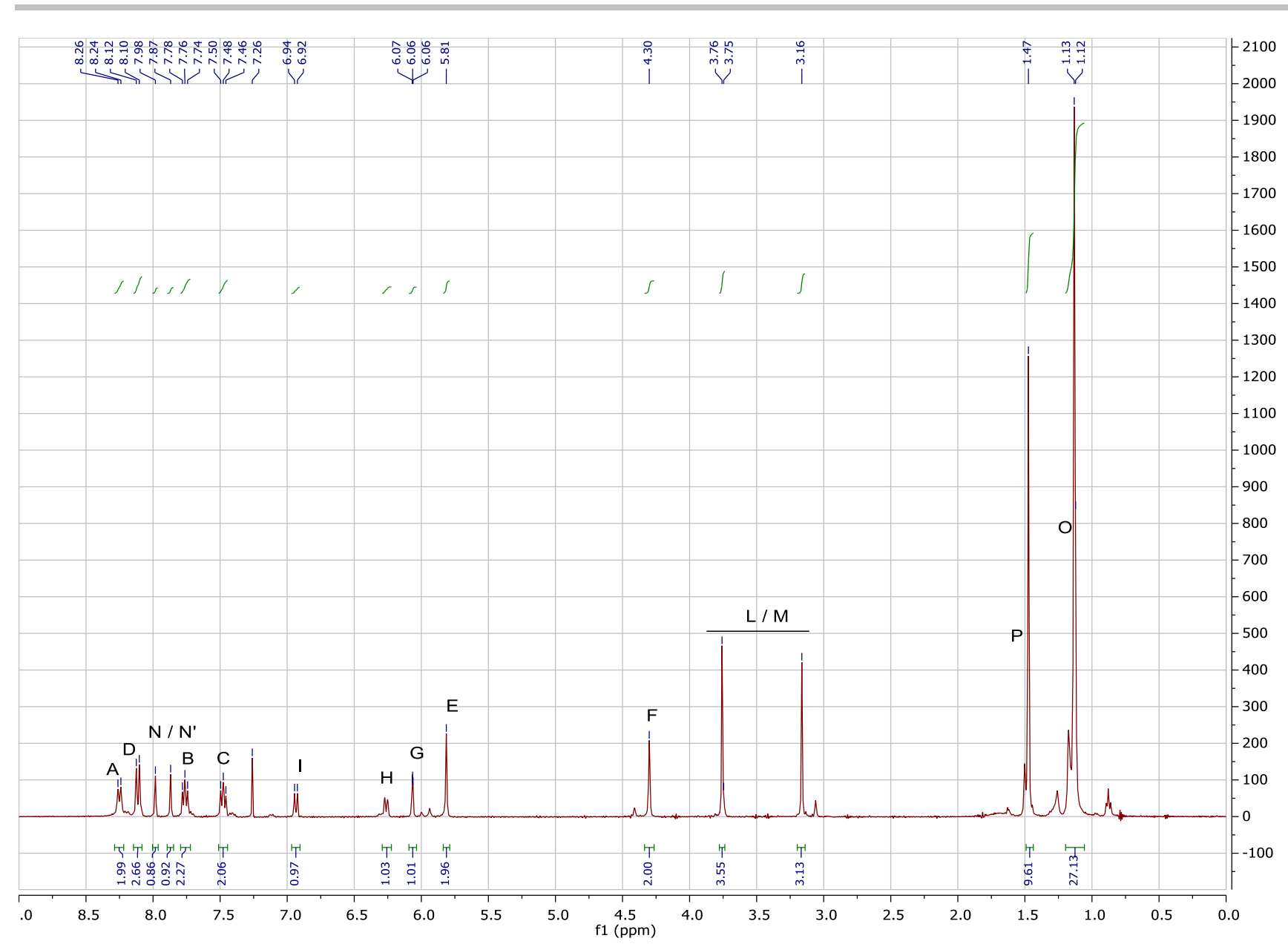

Figure S18. ${ }^{1} \mathrm{H}-\mathrm{NMR}\left(400 \mathrm{MHz}, \mathrm{CDCl}_{3}\right)$ of compund $\mathbf{5}$. 


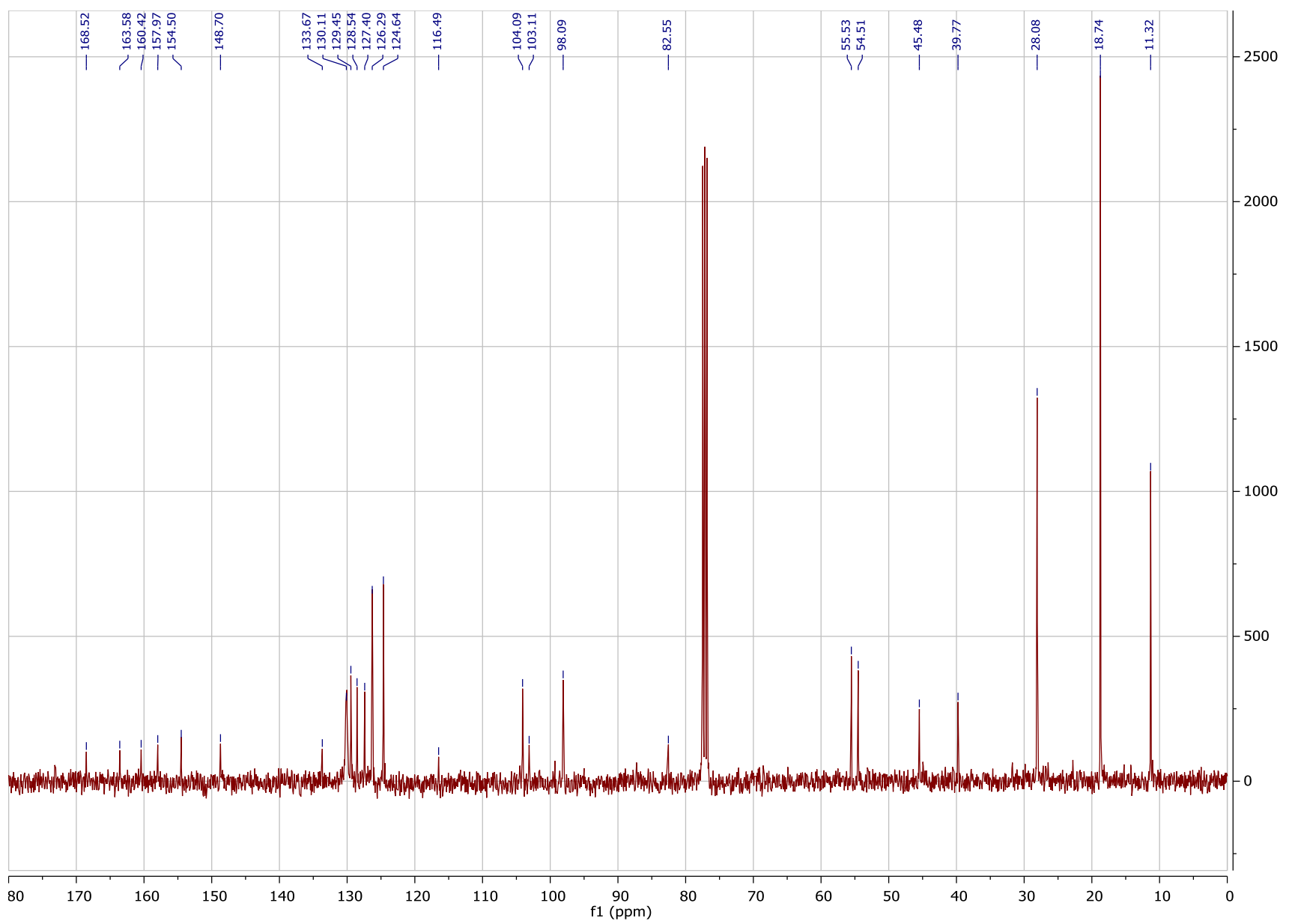

Figure S19. ${ }^{13} \mathrm{C}-\mathrm{NMR}\left(100 \mathrm{MHz}, \mathrm{CDCl}_{3}\right)$ of compund $\mathbf{5}$ 


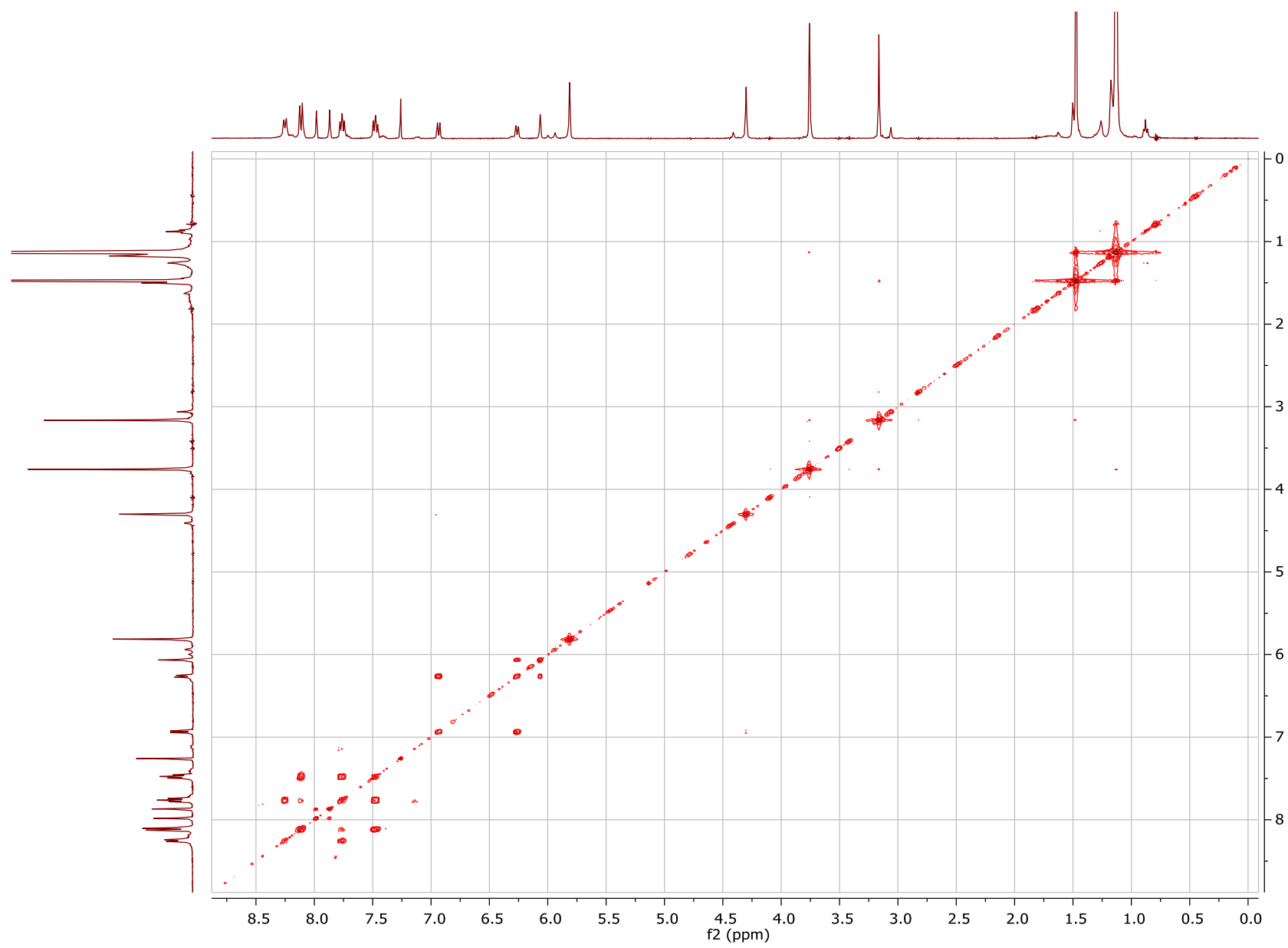

Figure S20. $\mathrm{HH}-\mathrm{COSY}\left(400 \mathrm{MHz}, \mathrm{CDCl}_{3}\right)$ of compund $\mathbf{5}$. 


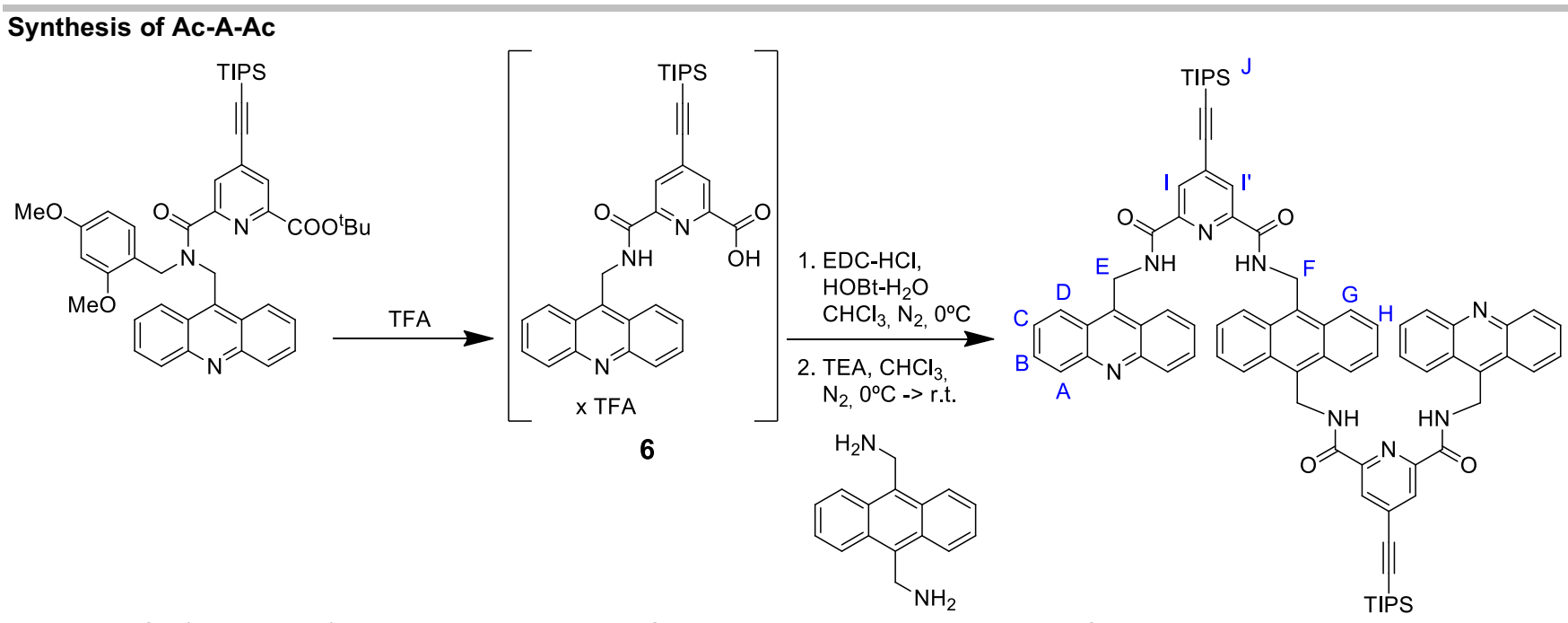

$799.4 \mathrm{mg}$ of $5(1.074 \mathrm{mmol})$ were dissolved in $20 \mathrm{ml}$ of TFA, the reaction was stirred at r.t. for 2 hours and the solvent was removed under reduced pressure. The product was suspended in $\mathrm{Et}_{2} \mathrm{O}$, filtered and washed with $\mathrm{Et}_{2} \mathrm{O}$, re-suspended in Toluene, filtered and washed with few $\mathrm{ml}$ of Tol, re-suspended in Acetone, filtered, washed with Acetone and $\mathrm{Et}_{2} \mathrm{O}$.

$577.1 \mathrm{mg}(599.9 \mathrm{mmol})$ obtained, white powder. $82 \%$ ( $80 \%$ purity by NMR)

(6) ${ }^{1} \mathrm{H}$ NMR (400 MHz, TFA-d) $\delta 9.18(\mathrm{~d}, J=8.9 \mathrm{~Hz}, 2 \mathrm{H}), 8.86(\mathrm{dd}, J=8.6,1.5 \mathrm{~Hz}, 2 \mathrm{H}), 8.75-8.61(\mathrm{~m}, 4 \mathrm{H}), 8.36(\mathrm{dd}, J=8.3,1.8 \mathrm{~Hz}$, $2 \mathrm{H}), 6.39(\mathrm{~s}, 2 \mathrm{H}) 1.73-1.28(\mathrm{~m}, 21 \mathrm{H})$, MS (MALDI): $\mathrm{m} / \mathrm{z}$ calcd. for $\mathrm{C}_{32} \mathrm{H}_{36} \mathrm{~N}_{3} \mathrm{O}_{3} \mathrm{Si}[\mathrm{M}+\mathrm{H}]^{+}:$: 538.252, found 538.406.

The product was used in the next step without further purification.

$165 \mathrm{mg}$ of $6(0.2539 \mathrm{mmol})$ and $43 \mathrm{mg}$ of $\mathrm{HOBt} \cdot \mathrm{H}_{2} \mathrm{O}(0.3174 \mathrm{mmol})$ were vacuum-dried and suspended in $15 \mathrm{ml}$ of dry chloroform under nitrogen atmosphere. $53 \mathrm{mg}$ of EDC $\cdot \mathrm{HCl}(0.2793 \mathrm{mmol})$ were added at $0^{\circ} \mathrm{C}$, the mixture was stirred at $0^{\circ} \mathrm{C}$ for $2 \mathrm{hours}$. $30 \mathrm{mg}$ of $7(0.1270 \mathrm{mmol})$ were added, followed by $177 \mu \mathrm{l}$ of triethylamine $(1.2695 \mathrm{mmol})$ and the mixture was allowed to warm to room temperature and stirred overnight with protection from light. The crude of reaction was adsorberd on celite and loaded into a column chromatography and eluted with $\mathrm{DCM} \rightarrow \mathrm{CHCl}_{3}$ (containing $0.6 \%$ of EtOH). The chromatographic separation has to be repeated and the product was finally triturated with $\mathrm{MeOH}$.

$39.9 \mathrm{mg}(0.0313 \mathrm{mmol})$ obtained, yellow solid. $25 \%$

${ }^{1} \mathrm{H}$ NMR (400 MHz, TFA-d) $\delta 8.71(\mathrm{~d}, J=9.0 \mathrm{~Hz}, 4 \mathrm{H}), 8.31(\mathrm{~d}, J=9.4 \mathrm{~Hz}, 4 \mathrm{H}), 8.29-8.13(\mathrm{~m}, 12 \mathrm{H}), 7.84(\mathrm{t}, J=7.7 \mathrm{~Hz}, 4 \mathrm{H}), 7.52$ $(\mathrm{dd}, J=7.1,3.2 \mathrm{~Hz}, 4 \mathrm{H}), 5.90(\mathrm{~s}, 2 \mathrm{H}), 5.78(\mathrm{~s}, 2 \mathrm{H}), 1.19-0.88(\mathrm{~m}, 42 \mathrm{H}),{ }^{13} \mathrm{C}$ NMR $(126 \mathrm{MHz}, \mathrm{TFA}) \delta 155.93,147.24,146.56$, $144.14,141.53,140.66,132.67,131.72,131.03,130.93,129.64,129.37,127.80,127.65,126.10,122.06,102.79,40.11,38.76$, 19.21, 12.96. MS (MALDI): $\mathrm{m} / \mathrm{z}$ calcd. for $\mathrm{C}_{80} \mathrm{H}_{83} \mathrm{~N}_{8} \mathrm{O}_{4} \mathrm{Si}_{2}[\mathrm{M}+\mathrm{H}]^{+}: 1275.607$, found 1276.033 


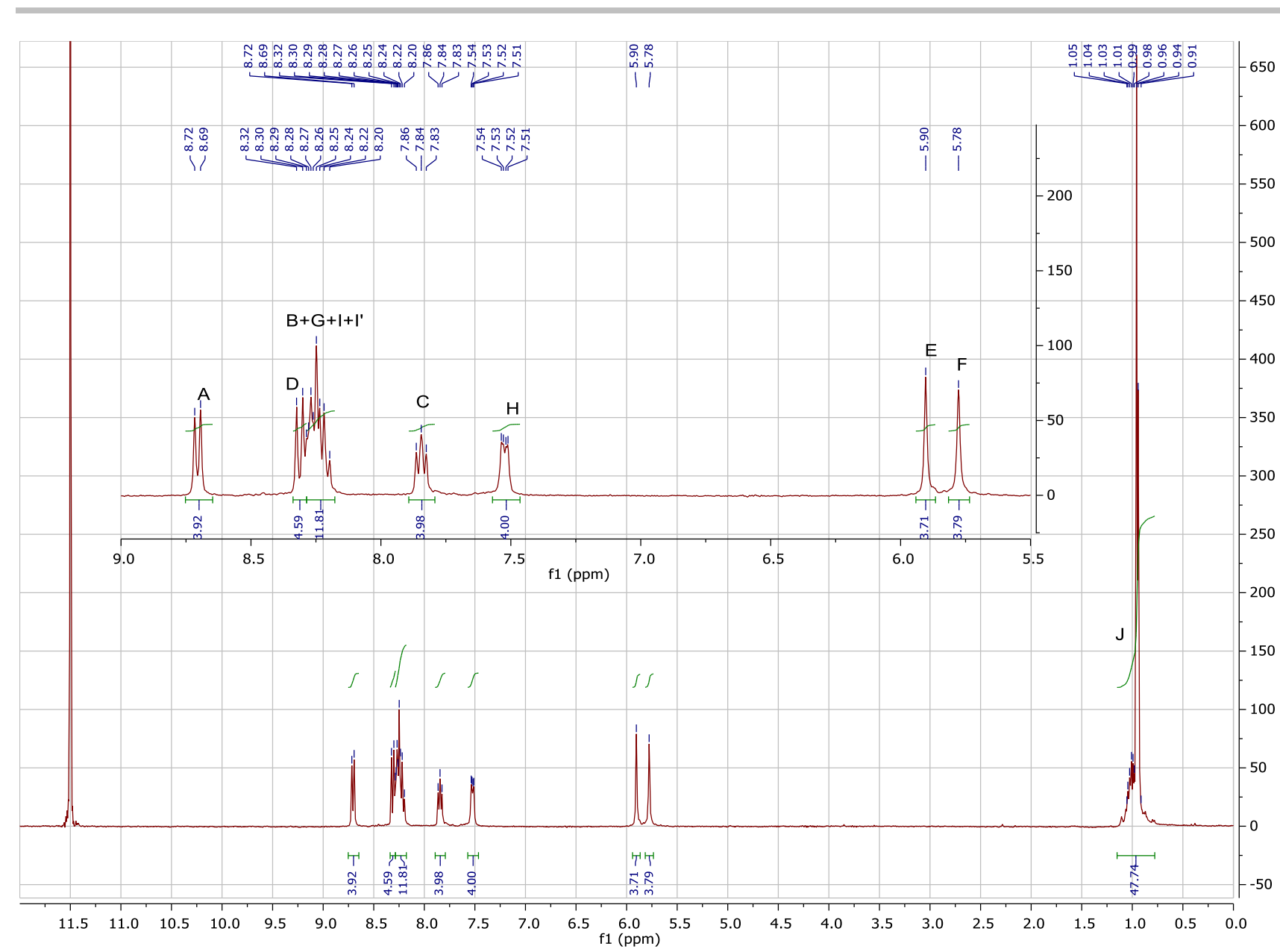

Figure S21. ${ }^{1} \mathrm{H}-\mathrm{NMR}(400 \mathrm{MHz}, \mathrm{TFA}-d)$ of compund Ac-A-Ac. 


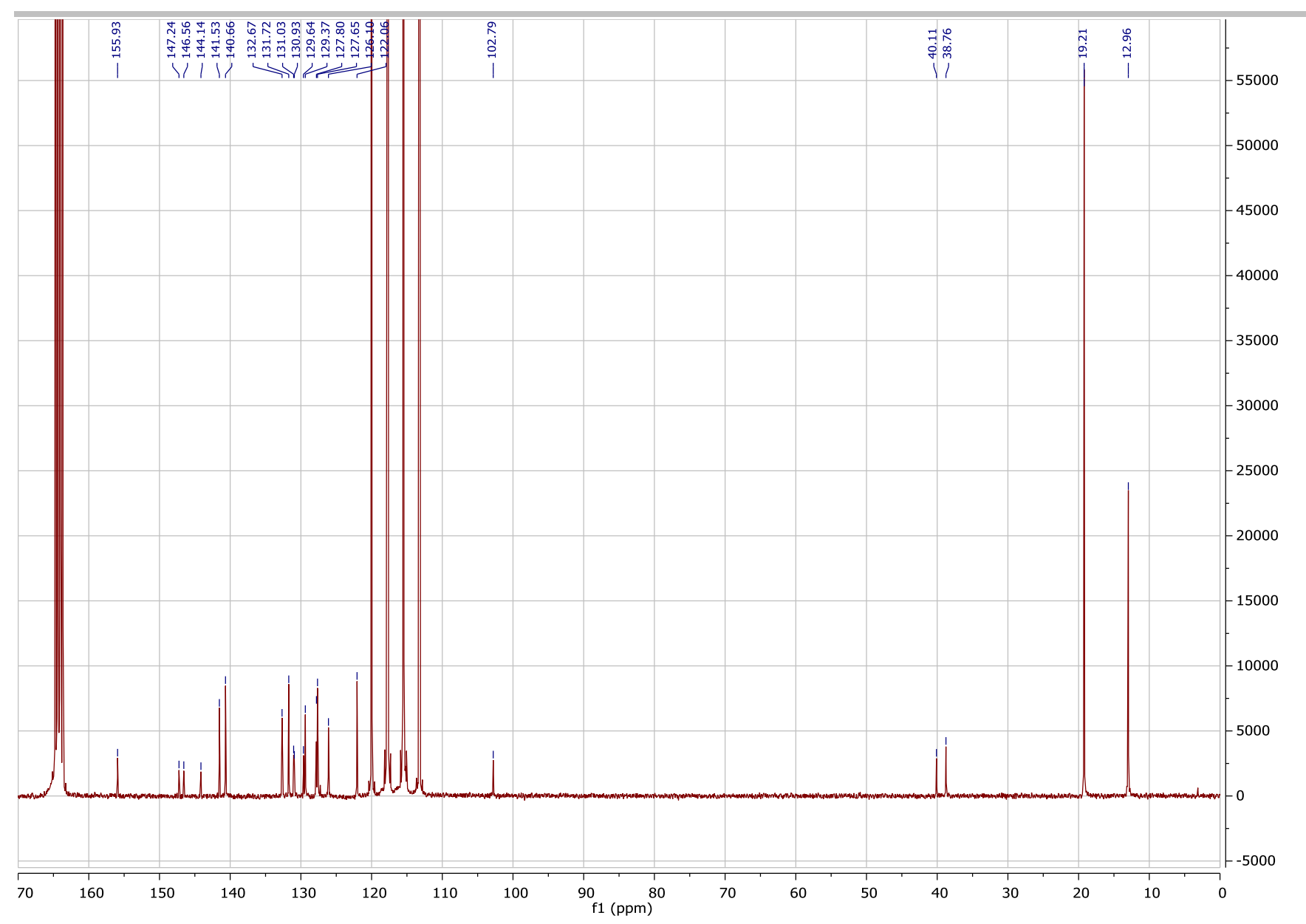

Figure S22. ${ }^{1} \mathrm{H}-\mathrm{NMR}(400 \mathrm{MHz}, \mathrm{TFA}-d)$ of compund Ac-A-Ac. 


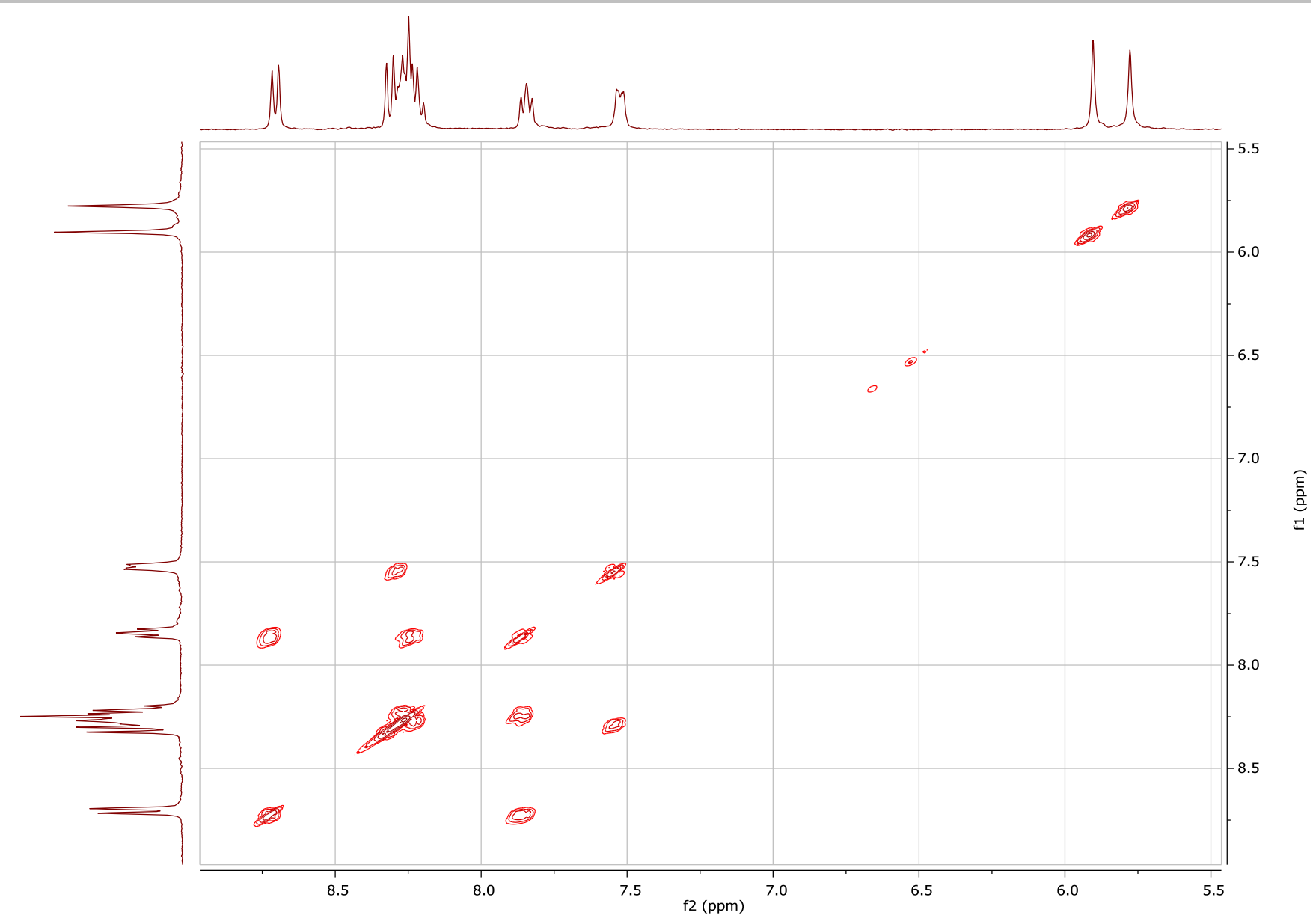

Figure S23. HH-COSY (400 MHz, TFA- $d$ ) of compund Ac-A-Ac. 
<smiles>O=C(O)c1cc(C#C[In]S)cc(C(=O)NCc2c3ccccc3nc3ccccc23)n1</smiles>

$x$ TFA

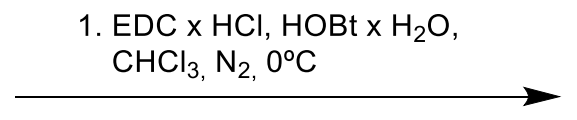

2. TEA, $\mathrm{CHCl}_{3}, \mathrm{~N}_{2}, 0^{\circ} \mathrm{C} \rightarrow>$ r.t.<smiles>CC(C)(C)OCc1ccccc1CNCc1c2ccccc2c(C[NH3+])c2ccccc12</smiles>

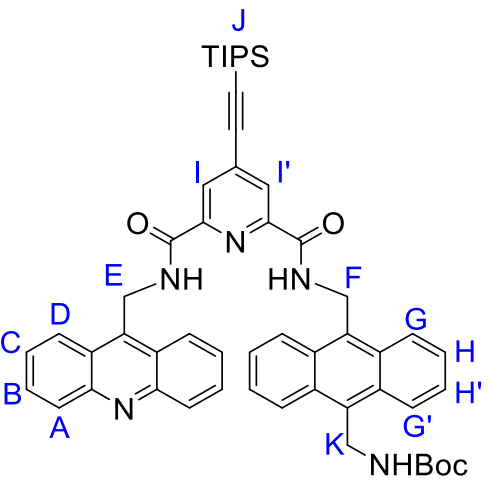

L

$50.0 \mathrm{mg}$ of $6(0.767 \mathrm{mmol}, 280 \%$ purity $)$ and $22.8 \mathrm{mg}$ of $\mathrm{HOBt} \cdot \mathrm{H}_{2} \mathrm{O}(0.1688 \mathrm{mmol})$ were vacuum-dried for 30 minutes and then suspended in $5 \mathrm{ml}$ of dry $\mathrm{CHCl}_{3}$ under nitrogen atmosphere. $32.4 \mathrm{mg}$ of $\mathrm{EDC} \cdot \mathrm{HCl}(0.1688 \mathrm{mmol})$ were added at $0^{\circ} \mathrm{C}$, the mixture was stirred at $0^{\circ} \mathrm{C}$ for $2 \mathrm{~h}$, then $71.5 \mathrm{mg}$ of $7 \mathrm{a}(0.1918 \mathrm{mmol})$ were added to the reaction, followed by $80 \mu \mathrm{l}$ of triethylamine $(0.5754 \mathrm{mmol})$. The mixture was allowed to warm to r.t. and was stirred overnight with protection from light. The reaction was diluted with $\mathrm{CHCl}_{3}$ and washed with water and BRINE. The organic phase was evaporated and the residue was suspended in $5 \mathrm{ml}$ of $\mathrm{AcOH}$ and filtered, the precipitate was washed with $\mathrm{AcOH}$ until it remains white and all the yellow product passed in the filtrate $(3 \times 5 \mathrm{ml})$. The solution was diluted with $\mathrm{CHCl}_{3}$ and washed with water, saturated $\mathrm{NaHCO}_{3}$ solution and BRINE. The product was purified by column chromatography in $\mathrm{CHCl}_{3} \rightarrow \mathrm{CHCl}_{3} / \mathrm{MeOH}$ 99:1 and was finally precipitated from $\mathrm{CHCl}_{3}$ to $\mathrm{MeOH}$.

$17.1 \mathrm{mg}$ obtained (light yellow solid). $26 \%$

${ }^{1} \mathrm{H}$ NMR $\left(500 \mathrm{MHz}, \mathrm{DMSO}-\mathrm{d}_{6}, 80^{\circ} \mathrm{C}\right) \delta 9.44(\mathrm{t}, J=6.1 \mathrm{~Hz}, 1 \mathrm{H}, \mathrm{NH}), 9.18(\mathrm{t}, J=6.1 \mathrm{~Hz}, 1 \mathrm{H}, \mathrm{NH}), 8.51(\mathrm{~d}, J=8.9 \mathrm{~Hz}, 6 \mathrm{H}), 8.14(\mathrm{~d}, J=$ $8.8 \mathrm{~Hz}, 2 \mathrm{H}), 8.12(\mathrm{~s}, 1 \mathrm{H}), 8.07(\mathrm{~s}, 1 \mathrm{H}), 7.79(\mathrm{dd}, J=8.5,6.7 \mathrm{~Hz}, 2 \mathrm{H}), 7.55(\mathrm{dd}, J=9.0,6.4 \mathrm{~Hz}, 2 \mathrm{H}), 7.45-7.35(\mathrm{~m}, 4 \mathrm{H}), 6.95(\mathrm{bs}, 1 \mathrm{H}$, $\mathrm{NH}), 5.52(\mathrm{~d}, J=5.7 \mathrm{~Hz}, 2 \mathrm{H}), 5.50(\mathrm{~d}, J=5.9 \mathrm{~Hz}, 2 \mathrm{H}), 5.19(\mathrm{~d}, J=5.6 \mathrm{~Hz}, 2 \mathrm{H}), 1.42(\mathrm{~s}, 9 \mathrm{H}), 1.21-1.05(\mathrm{~m}, 21 \mathrm{H}),{ }^{13} \mathrm{C} \mathrm{NMR}(126$ $\mathrm{MHz}$, DMSO-d $\left.\mathrm{d}_{6}, 80^{\circ} \mathrm{C}\right) \delta 162.21,161.92,149.18,149.04,147.90,140.20,132.60,129.61,129.29,125.50,125.13,124.99,124.77$, 124.55, 124.48, 102.88, 98.28, 36.42, 35.47, 34.70, 27.85, 17.90, 10.26, MS (MALDI): m/z calcd. for $\mathrm{C}_{53} \mathrm{H}_{58} \mathrm{~N}_{5} \mathrm{O}_{4} \mathrm{Si}[\mathrm{M}+\mathrm{H}]^{+}: 856.425$, found 856.833, $\mathrm{C}_{53} \mathrm{H}_{57} \mathrm{~N}_{5} \mathrm{O}_{4} \mathrm{SiNa}[\mathrm{M}+\mathrm{Na}]^{+}$: 878.407, found 878.805, $\mathrm{C}_{106} \mathrm{H}_{114} \mathrm{~N}_{10} \mathrm{O}_{8} \mathrm{Si}_{2} \mathrm{Na}[2 \mathrm{M}+\mathrm{Na}]^{+}$: 1733.825, found 1733.450 . 


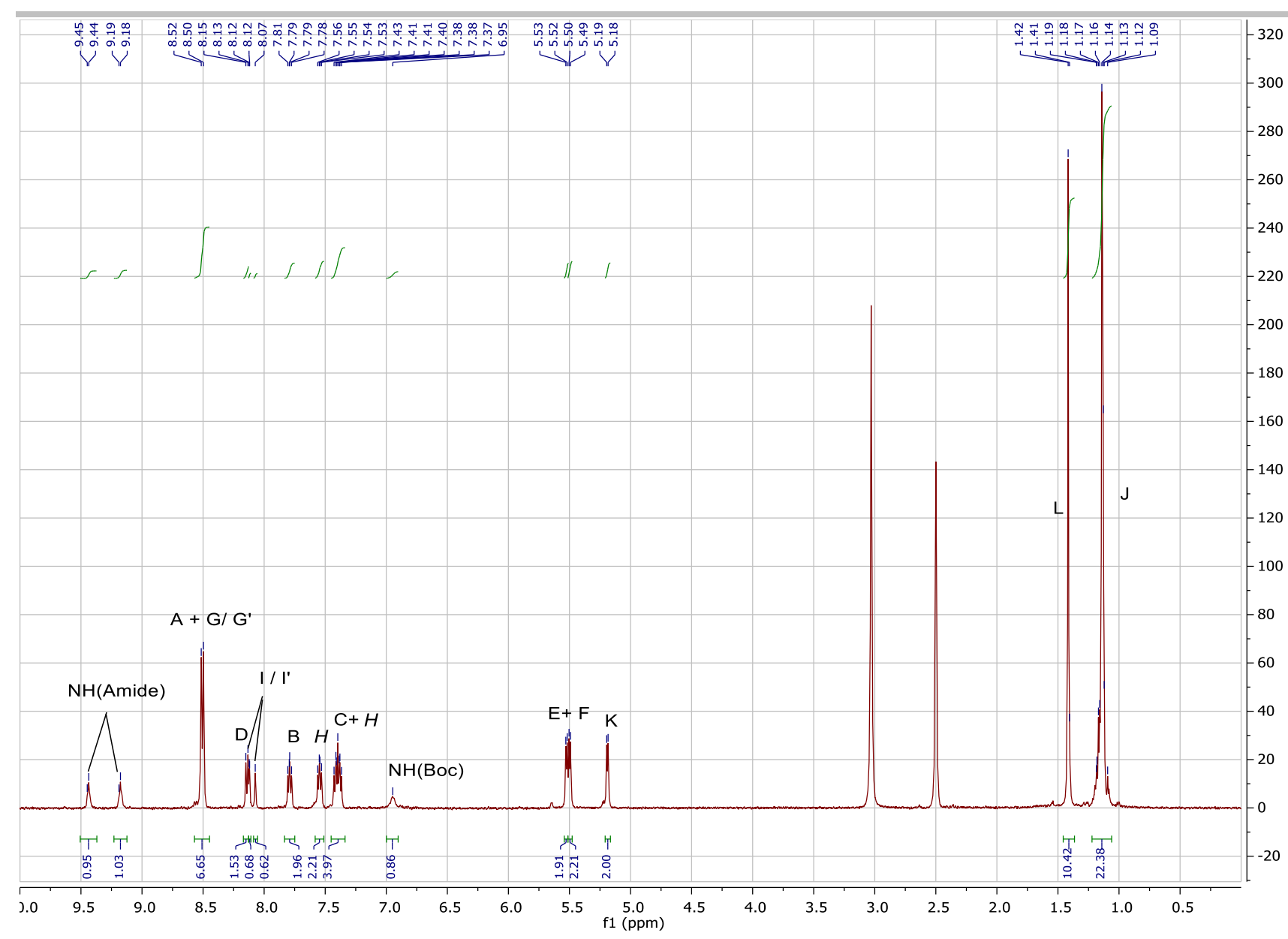

Figure S24. ${ }^{1} \mathrm{H}-\mathrm{NMR}\left(500 \mathrm{MHz}, \mathrm{DMSO}-d_{3}, 80^{\circ} \mathrm{C}\right)$ of compund Ac-A 


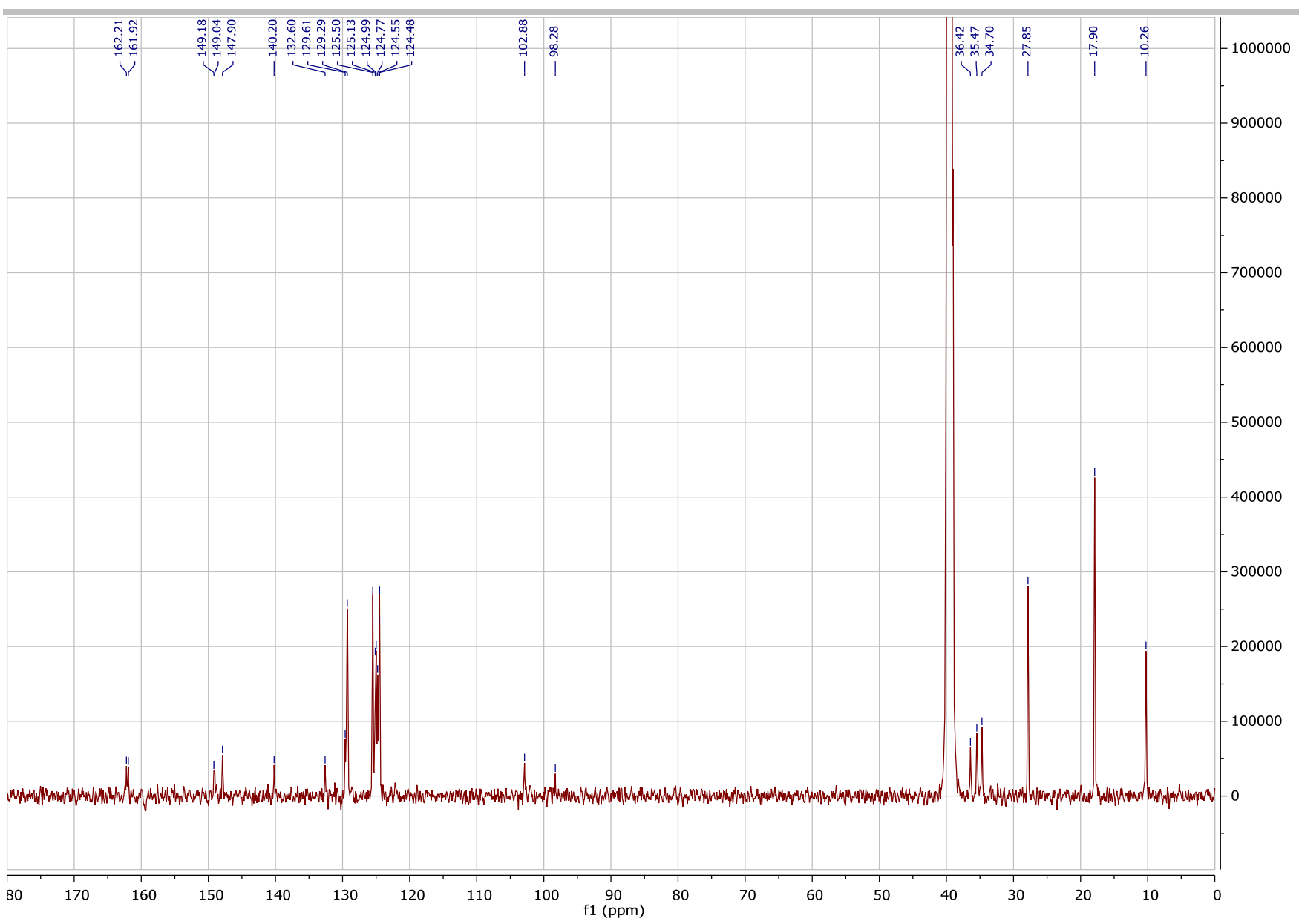

Figure S25. ${ }^{13} \mathrm{C}-\mathrm{NMR}\left(125 \mathrm{MHz}\right.$, DMSO- $\left.d_{6}, 80^{\circ} \mathrm{C}\right)$ of compund Ac-A. 


\section{Computer Models}
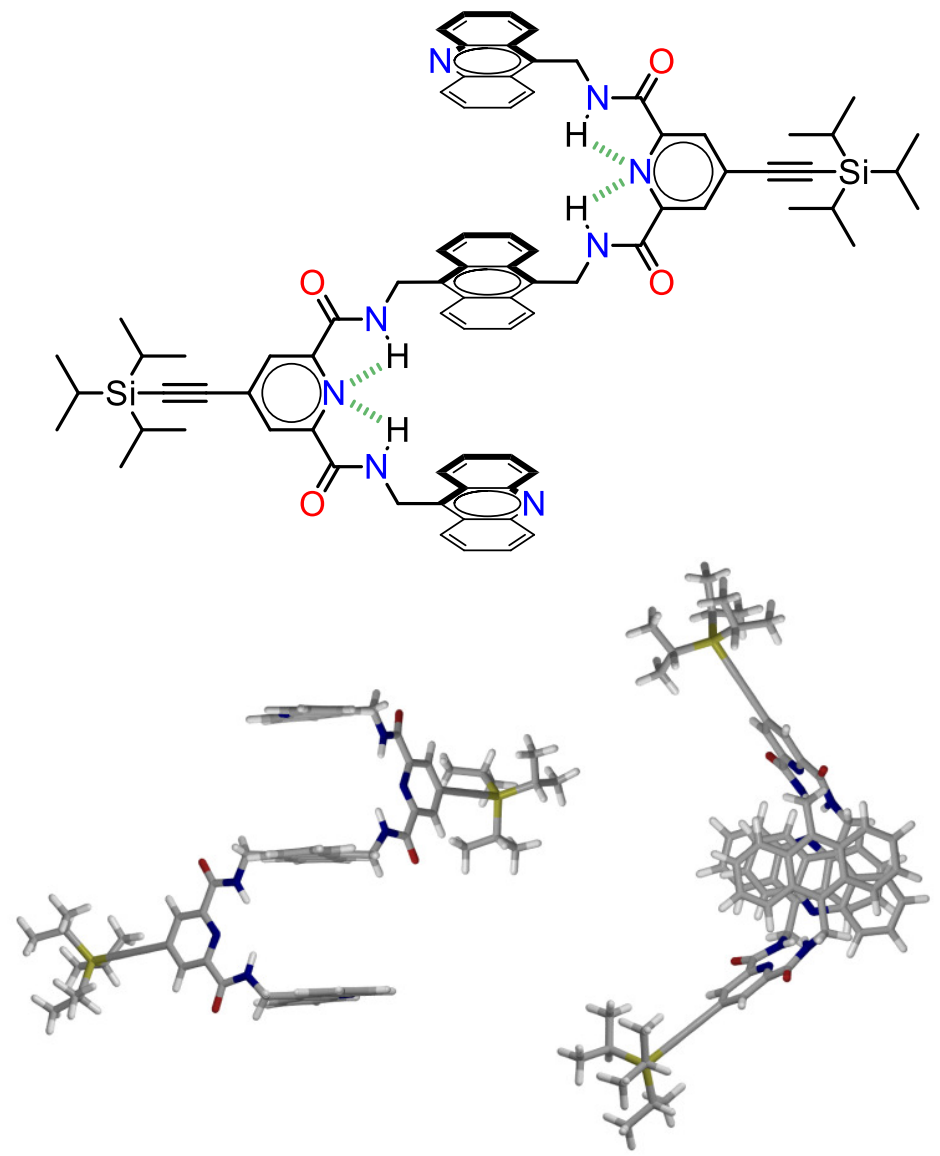

Figure S26. Structure of Ac-A-Ac monomer chemical structure (top), and 3D atomic view in the polymerizable conformation, side (bottom left) and top (bottom right) views. 


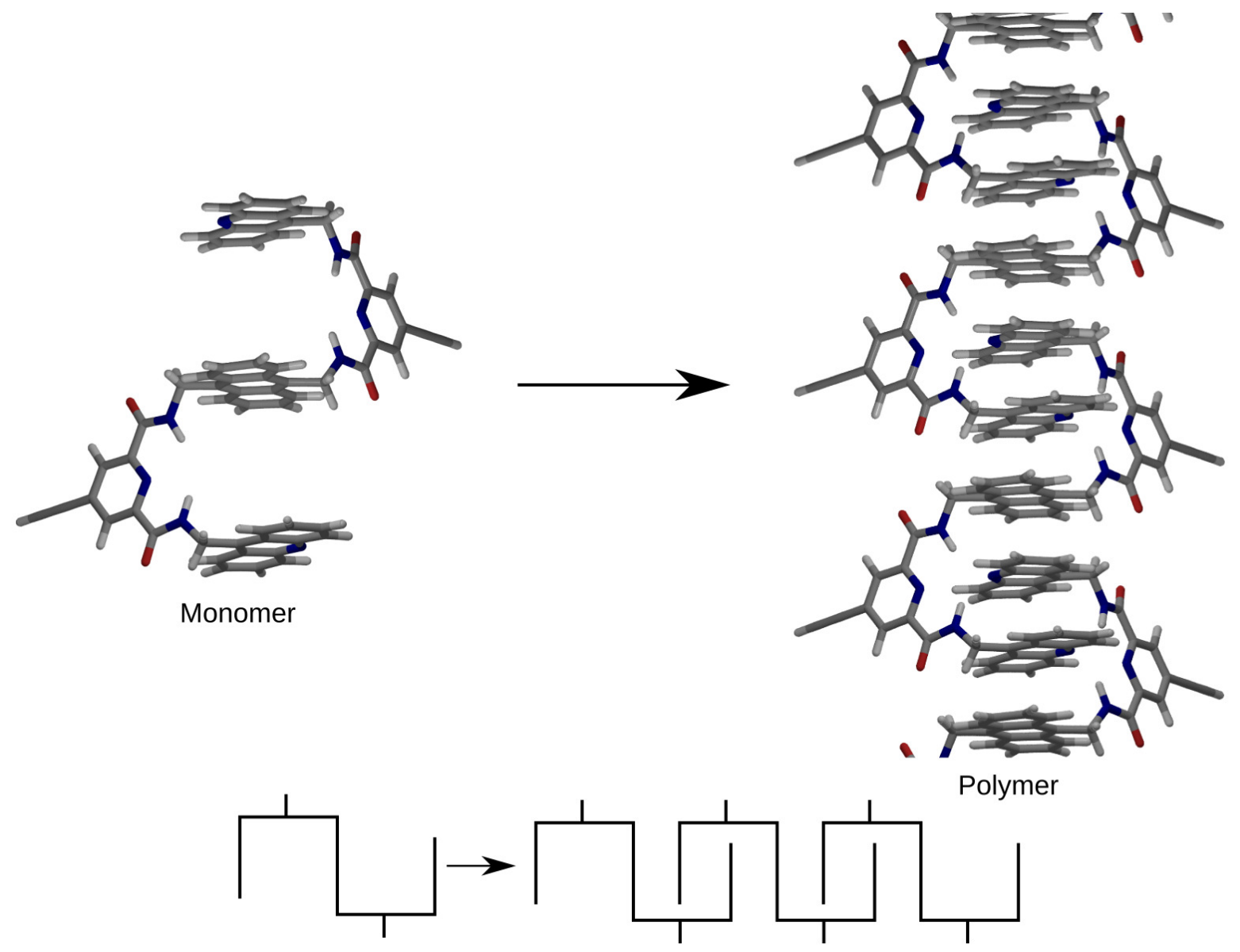

Figure S27. Polymerization of Ac-A-Ac represented in 3D form (top) and as an idealized scheme (bottom). Aromatic core molecule (without triisobutylsilyl groups) as modelled (AC-A-Ac'). 


\section{Density Functional Tight Binding Models}

A Semi-empirical, Density Functional Theory Tight Binding (DFTB), Hamiltonian was used as a fast, yet relatively accurate alternative to DFT to screen and probe different possible conformations of the polymer. For this, 1D periodic structures with one and two molecules per unit cell were optimized using the $3 \mathrm{OB}$ parameter set with vdW empirical corrections with and without a hydrogen bonding term, DFTB-D3H5 and DFTB-D3 respectively. In order to ensure that interactions between cells could be neglected, the cell box sides were set to $50 \AA$. The hydrogen-bond corrected Hamiltonian showed slightly larger unit cells and larger binding energies, Table S1. We performed MD to explore configurational space and try to reach the most representative minima possible. This procedure found an almost isoenergetic minimum (difference lower than chemical accuracy) where the two monomer molecules in the unit cell present different relative orientations, Figure S28.

\begin{tabular}{|c|c|c|c|c|c|}
\hline & & Total Energy & 1D Periodicity & Band Gap & $\begin{array}{c}\text { Intermolecular } \\
\text { Energy }\end{array}$ \\
\hline & Monomers / UC & $\mathrm{eV}$ & $\AA$ & $\mathrm{eV}$ & $\mathrm{kcal} / \mathrm{mol}$ \\
\hline 3OB/DFT-D3 & 1 & -4201.362 & 9.976 & 1.844 & -- \\
\hline 3OB/DFT-D3 & 2 & -8402.728 & 19.908 & 1.850 & -132.868 \\
\hline 3OB/DFT-D3H5 & 1 & -4198.703 & 10.113 & 1.683 & -- \\
\hline 3OB/DFT-D3H5 & 2 & -8397.405 & 20.179 & & -153.398 \\
\hline $\begin{array}{c}\text { 3OB/DFT-D3H5 } \\
\text { (after MD) }\end{array}$ & 2 & -8397.563 & 19.837 & 1.498 & -154.317 \\
\hline
\end{tabular}

Table S1. DFTB+ optimization of 1D polymers with 1 and 2 monomers per unit cell. *: best minimum obtained after MD simulations.

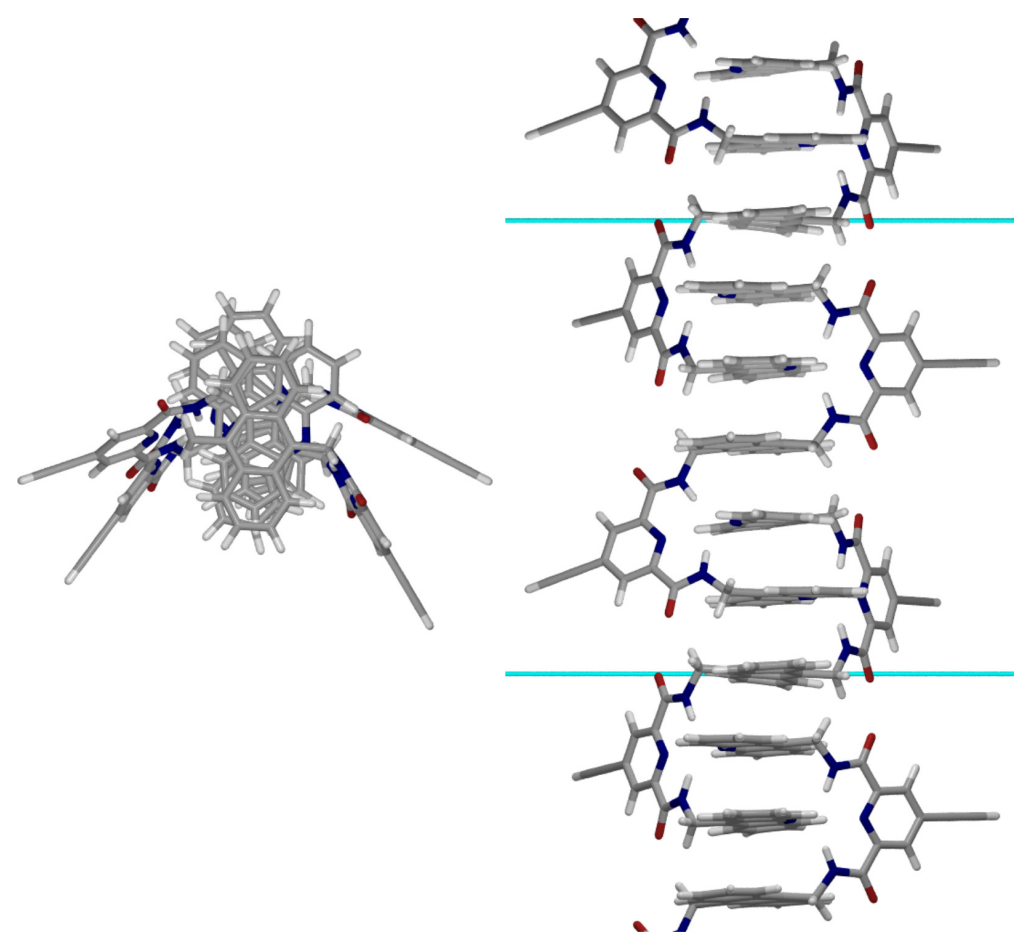

Figure S28. Best minimum (after MD simulations) top (left) and side (right) views. 


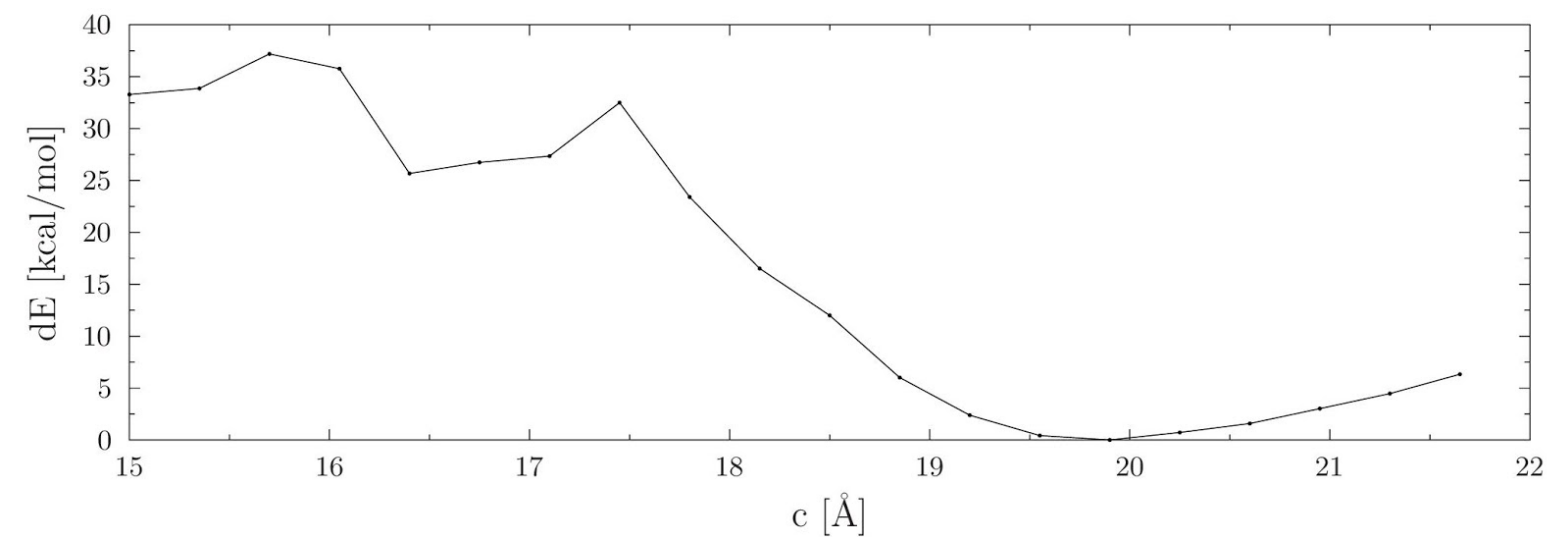

Figure S29. Energy difference at the 3OB/DFTB-D3H5 level as a function of unit cell length. 


\section{DFT Models (Geometries)}

Density Functional Theory (DFT) was used to improve and confirm the DFTB findings. Models were computed with the Fritz Haber Institute ab initio molecular simulations (FHI-aims) package ${ }^{[2-4]}$ utilizing "light" numeric atomic orbitals. These atomic orbitals set approximately correspond to a TZVP Gaussian basis set. Two functionals, PBE and BLYP, were tried for geometry optimization, while the B3LYP functional was used to compute HOMO-LUMO gaps and frontier orbitals. Dispersion interactions are fundamental for a proper description of the stacking of acridines and anthracene. PBE and BLYP functionals were augmented with TKatchenkoScheffler ${ }^{[5]}$ and Many-body van der Waals ${ }^{[5]}$ corrections, -vdW or $-\mathrm{MBD}$, respectively. The minima geometries were considered converged after the maximum atomic force was below $0.002 \mathrm{eV} / \AA$, as lower values were not easy to achieve due to the presence of spurious small forces from neighbouring unit cells. Remarkably the binding energies are similar to what computed with DFTB, and the same minimum is found with similar energetic differences, thus confirming the accuracy of the findings at the DFTB level.

\begin{tabular}{|c|c|c|c|c|c|}
\hline method (// geometry) & Monomers / UC & Total Energy & $\begin{array}{c}1 \mathrm{D} \\
\text { Periodicity }\end{array}$ & Band Gap & $\begin{array}{c}\text { Intermolecular } \\
\text { Energy }\end{array}$ \\
\hline BLYP-vdW & & $\mathrm{eV}$ & $\AA$ & $\mathrm{eV}$ & $\mathrm{kcal} / \mathrm{mol}$ \\
\hline BLYP-vdW & 1 & -85108.863 & 9.825 & 1.776 & \\
\hline PBE-MBD & 2 & -170217.728 & 19.663 & 1.650 & \\
\hline PBE-MBD & 1 & -85019.595 & 10.614 & 1.678 & -122.442 \\
\hline PBE-MBD (after MD)* & 2 & -170039.207 & 21.074 & 1.620 & -123.191 \\
\hline B3LYP // PBE-MBD & 2 & -170039.300 & 20.631 & 1.525 & \\
\hline $\begin{array}{c}\text { B3LYP // PBE-MBD } \\
\begin{array}{c}\text { B3LYP // PBE-MBD } \\
(\text { after MD) }\end{array}\end{array}$ & 1 & -85113.899 & 10.614 & 2.801 & \\
\hline
\end{tabular}

Table S2. BLYP-vdW and PBE-MBD geometry optimizations and B3LYP values on PBE-MBD with the light numerical orbitals. *: Best minimum obtained after MD simulations at the DFTB level.

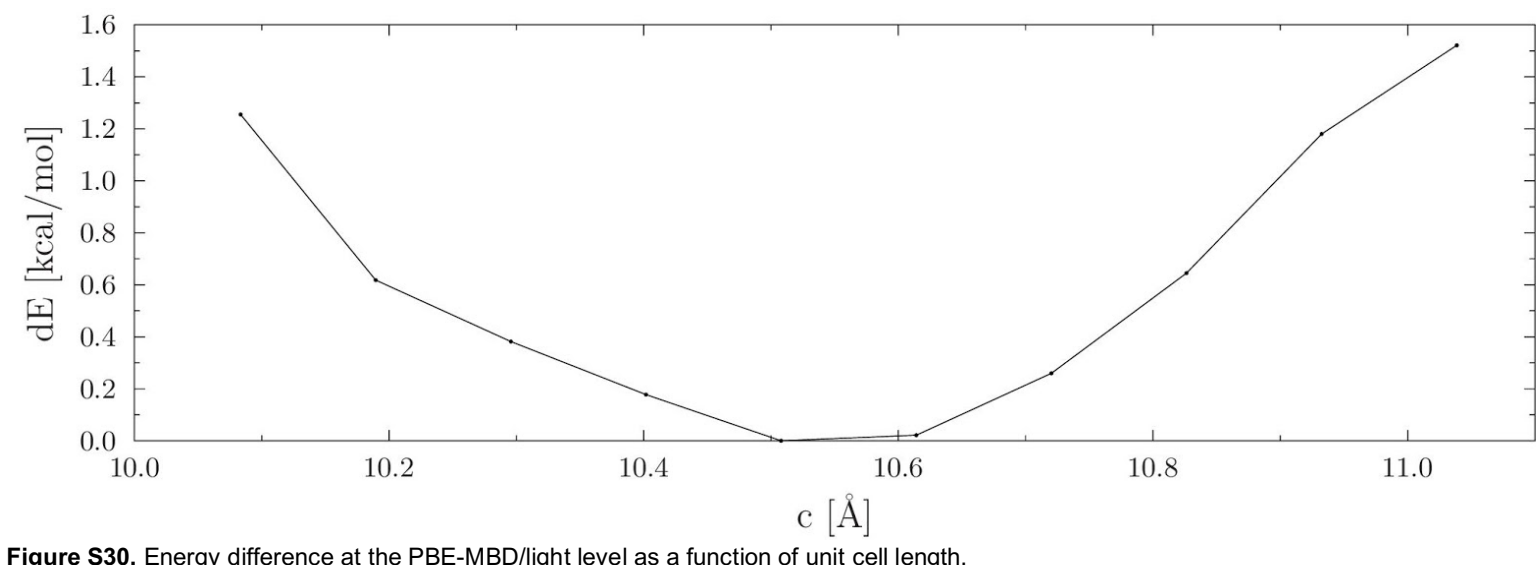

Figure S30. Energy difference at the PBE-MBD/light level as a function of unit cell length. 


\section{DFT Models (Frontier Orbitals)}

The frontier orbitals were computed in order to understand how frontier electrons are distributed in the polymeric material at the band gap energies. Although a monomer 1D unit cell represents properly a structural minimum, it was found that at least two points in reciprocal space were needed to convergence the total energy. Considering this, to check the accuracy of the electron distribution computed in real space, unit cells with 1, 2 and 3 monomers were computed at the $\Gamma$-point at the B3LYP level and compared, Figure S31. Larger cells were made by replication of the monomer unit cell structure computed at the PBE-MBD level. This comparison shows that although most features for frontier electrons for all the three systems are common for the three systems, some small differences can be observed in some densities for the monomer. This shows, that electronically, real space calculations need at least two monomers in the unit cell to be accurate. In addition, we compared orbitals for the two isoenergetic two monomer unit cells minimized at the PBE-MBD level, Figure S12. Although the degeneracy is lifted due to the more extended asymmetry, the fundamental features of the frontier orbitals are preserved.
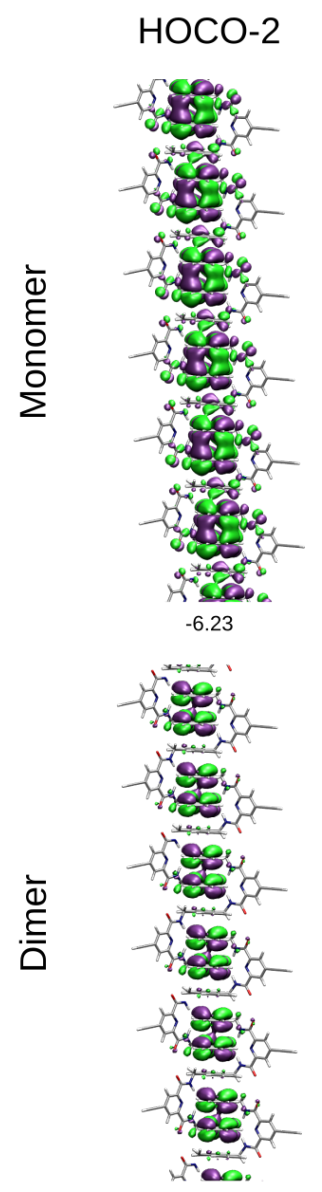

$-5.93$

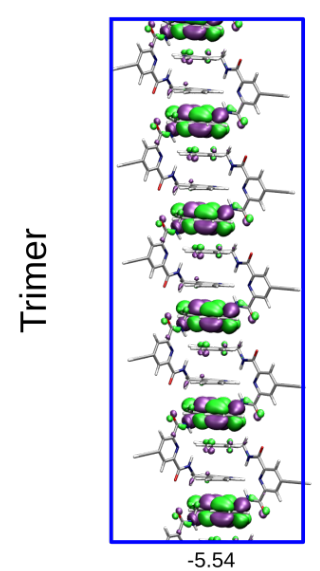

HOCO-1

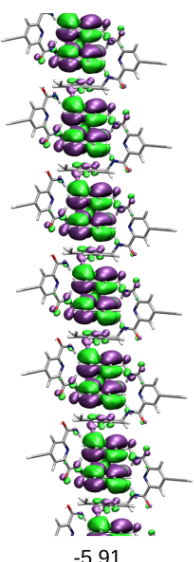

5.91

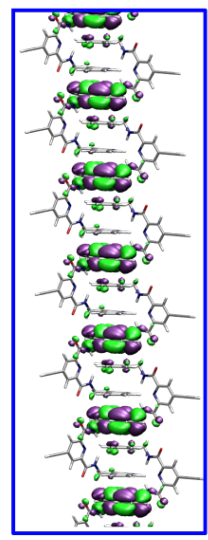

$-5.54$

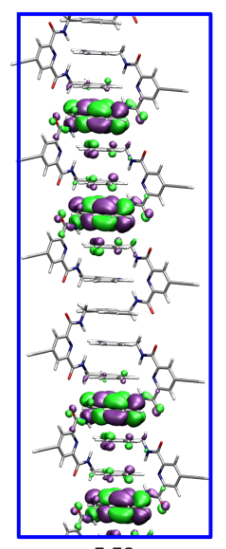

$-5.53$
$\mathrm{HOCO}$

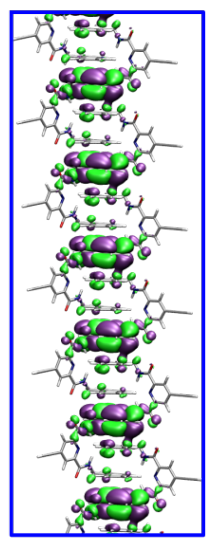

$-5.51$

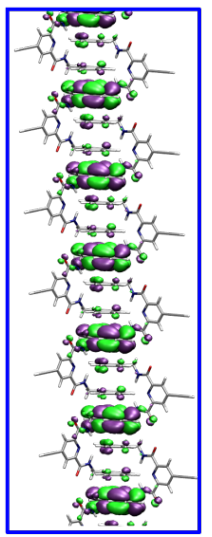

$-5.53$

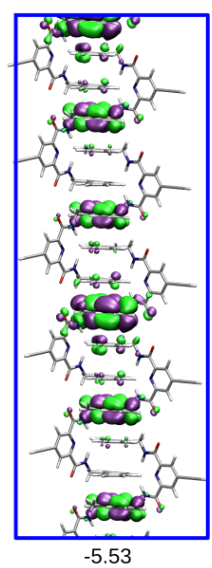

LUCO

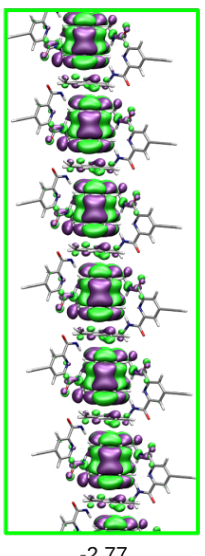

$-2.77$

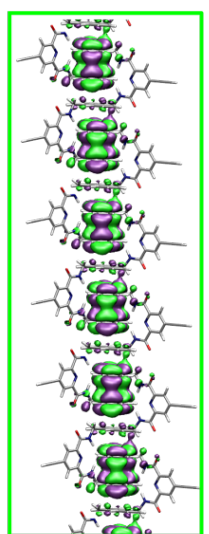

$-2.81$

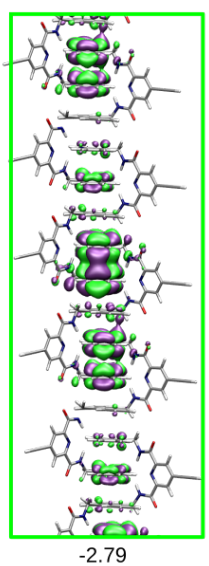

LUCO+1

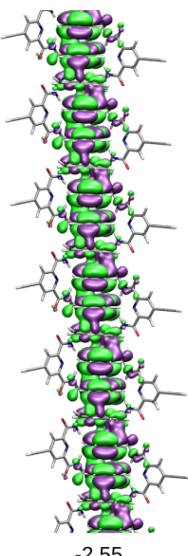

$-2.55$

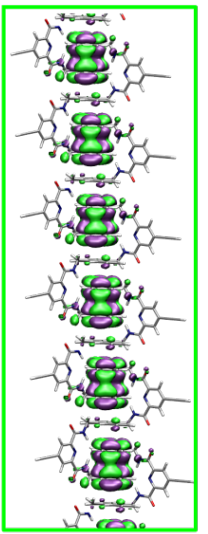

$-2.74$

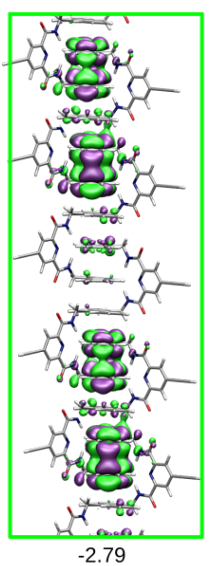

$\mathrm{LUCO}+2$

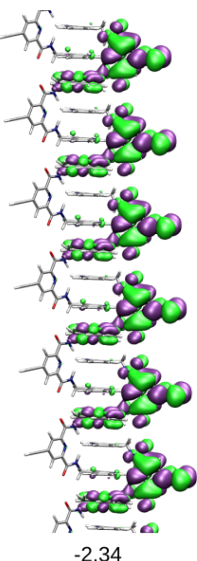

(6)

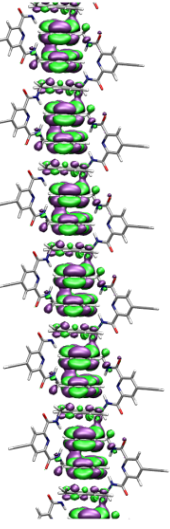

$-253$

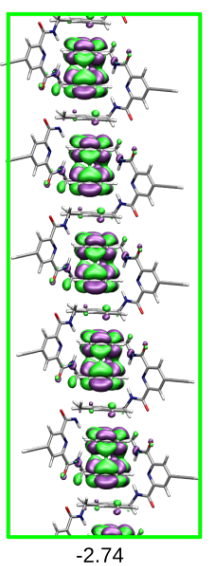

Figure S31. Frontier orbitals of one monomer (top), two monomers (center) and three monomers (bottom) unit cells constructed by replication of the monomer PBE-MBD/light structure computed with a B3LYP/light Hamiltonian. Frontier orbitals are marked by boxes. 


\section{Author Contributions}

M.C. developed the synthetic route and performed the characterizations and the titrations; M.M. synthetized the precursors and the polymer in larger scale; K.S. and M.M.-F. performed the theoretical calculations; A.S. carried out the TRMC measurements and interpreted the data; M.C. and A.M.-A wrote the paper with the input from all authors; A.M.-A. conceived and supervised the study.

\section{References}

[1] M. Carini, M. P. Ruiz, I. Usabiaga, J. A. Fernández, E. J. Cocinero, M. Melle-Franco, I. Diez-Perez, A. Mateo-Alonso, Nat. Commun. 2017, 8, 15195. V. Blum, R. Gehrke, F. Hanke, P. Havu, V. Havu, X. Ren, K. Reuter, M. Scheffler, Comput. Phys. Commun. 2009, 180, $2175-2196$.

[3] A. Marek, V. Blum, R. Johanni, V. Havu, B. Lang, T. Auckenthaler, A. Heinecke, H. J. Bungartz, H. Lederer, J. Phys.: Condens. Matter 2014, $26,213201$.

[4] V. W.-z. Yu, F. Corsetti, A. García, W. P. Huhn, M. Jacquelin, W. Jia, B. Lange, L. Lin, J. Lu, W. Mi, A. Seifitokaldani, Á. Vázquez-Mayagoitia, C. Yang, H.

Yang, V. Blum, Comput. Phys. Commun. 2018, 222, 267-285

[5] A. Tkatchenko, M. Scheffler, Phys. Rev. Lett. 2009, 102, 073005. 
